\title{
Resorbable versus titanium plates for orthognathic surgery
}

\author{
Agnihotry, A
}

http://hdl.handle.net/10026.1/10437

10.1002/14651858.cd006204.pub3

Cochrane Database of Systematic Reviews

Wiley

All content in PEARL is protected by copyright law. Author manuscripts are made available in accordance with publisher policies. Please cite only the published version using the details provided on the item record or document. In the absence of an open licence (e.g. Creative Commons), permissions for further reuse of content should be sought from the publisher or author. 


\section{(E) Cochrane Library}

Cochrane Database of Systematic Reviews

\section{Resorbable versus titanium plates for orthognathic surgery (Review)}

Agnihotry A, Fedorowicz Z, Nasser M, Gill KS

Agnihotry A, Fedorowicz Z, Nasser M, Gill KS.

Resorbable versus titanium plates for orthognathic surgery.

Cochrane Database of Systematic Reviews 2017, Issue 10. Art. No.: CD006204.

DOI: 10.1002/14651858.CD006204.pub3.

www.cochranelibrary.com 


\section{TABLE OF CONTENTS}

HEADER

ABSTRACT

PLAIN LANGUAGE SUMMARY

. . . . . . . . . . . . . . . . . . . . . . . . . . . . . 2

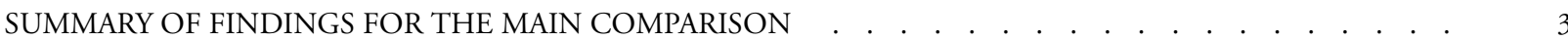

BACKGROUND . . . . . . . . . . . . . . . . . . . . . . . . . . . . . . . . . . . . . . . . 6

OBJECTIVES . . . . . . . . . . . . . . . . . . . . . . . . . . . . . . . . . . . . . 6

METHODS . . . . . . . . . . . . . . . . . . . . . . . . . . . . . . . . . . . . . . 6

RESULTS . . . . . . . . . . . . . . . . . . . . . . . . . . . . . . . . . . . . . 9

Figure 1. . . . . . . . . . . . . . . . . . . . . . . . . . . . . . . . . 10

Figure 2. . . . . . . . . . . . . . . . . . . . . . . . . . . . . . . . . . . . . . 12

Figure $3 . \quad$. . . . . . . . . . . . . . . . . . . . . . . . . . . . . . . . . . . . . .

DISCUSSION . . . . . . . . . . . . . . . . . . . . . . . . . . . . . . . . . . . . . . . . . . . . . . .

AUTHORS' CONCLUSIONS . . . . . . . . . . . . . . . . . . . . . . . . . . . . . . . . . . . . . . . 17

ACKNOWLEDGEMENTS . . . . . . . . . . . . . . . . . . . . . . . . . . . . . . . . . . . . . . . 17

REFERENCES . . . . . . . . . . . . . . . . . . . . . . . . . . . . . . . . . . . . . . . . 18

CHARACTERISTICS OF STUDIES . . . . . . . . . . . . . . . . . . . . . . . . . . . . . . . . . . . 19

DATA AND ANALYSES . . . . . . . . . . . . . . . . . . . . . . . . . . . . . . . . . . . . . . . 24

Analysis 1.1. Comparison 1 Resorbable versus titanium plating, Outcome 1 Postoperative pain (wound discomfort) VAS $(0-10)$. . . . . . . . . . . . . . . . . . . . . . . . . . . . . . . . . . . . . 24

Analysis 1.2. Comparison 1 Resorbable versus titanium plating, Outcome 2 Patient satisfaction 4-6 months postoperative. 25 ADDITIONAL TABLES . . . . . . . . . . . . . . . . . . . . . . . . . . . . . . . . . . . . . . . . . 25 APPENDICES . . . . . . . . . . . . . . . . . . . . . . . . . . . . . . . . . . . . . . . . . WHAT'S NEW . . . . . . . . . . . . . . . . . . . . . . . . . . . . . . . . . . . . . . 28

HISTORY . . . . . . . . . . . . . . . . . . . . . . . . . . . . . . . . . . . . . 29

CONTRIBUTIONS OF AUTHORS . . . . . . . . . . . . . . . . . . . . . . . . . . . . . . . . . . . 29

DECLARATIONS OF INTEREST . . . . . . . . . . . . . . . . . . . . . . . . . . . . . . . . . . . . . . . 29

SOURCES OF SUPPORT . . . . . . . . . . . . . . . . . . . . . . . . . . . . . . . . . . . . . . . . . . . .

NOTES . . . . . . . . . . . . . . . . . . . . . . . . . . . . . . . . . . . . . . . . . 30

INDEX TERMS . . . . . . . . . . . . . . . . . . . . . . . . . . . . . . . . . . . . 30 
[Intervention Review]

\title{
Resorbable versus titanium plates for orthognathic surgery
}

\author{
Anirudha Agnihotry ${ }^{1}$, Zbys Fedorowicz ${ }^{2}$, Mona Nasser $^{3}$, Karanjot S Gill ${ }^{4}$ \\ ${ }^{1}$ Arthur A Dugoni School of Dentistry, University of the Pacific, San Francisco, CA, USA. ${ }^{2}$ Bahrain Branch, Cochrane, Awali, Bahrain. \\ ${ }^{3}$ Peninsula Dental School, Plymouth University Peninsula Schools of Medicine and Dentistry, Plymouth, UK. ${ }^{4}$ University of Detroit \\ Mercy School of Dentistry, Detroit, Michigan, USA \\ Contact address: Anirudha Agnihotry, Arthur A Dugoni School of Dentistry, University of the Pacific, 155 5th Street, San Francisco, \\ CA, 94103, USA. anirudha.agnihotry@gmail.com. \\ Editorial group: Cochrane Oral Health Group. \\ Publication status and date: Stable (no update expected for reasons given in 'What's new'), published in Issue 11, 2017.
}

Citation: Agnihotry A, Fedorowicz Z, Nasser M, Gill KS. Resorbable versus titanium plates for orthognathic surgery. Cochrane Database of Systematic Reviews 2017, Issue 10. Art. No.: CD006204. DOI: 10.1002/14651858.CD006204.pub3.

Copyright (C) 2017 The Cochrane Collaboration. Published by John Wiley \& Sons, Ltd.

\begin{abstract}
A B S T R A C T
Background

Recognition of some of the limitations of titanium plates and screws used for the fixation of bones has led to the development of plates manufactured from bioresorbable materials. Whilst resorbable plates appear to offer clinical advantages over metal plates in orthognathic surgery, concerns remain about the stability of fixation and the length of time required for their degradation and the possibility of foreign body reactions. This review compares the use of titanium versus bioresorbable plates in orthognathic surgery and is an update of the Cochrane Review first published in 2007.
\end{abstract}

\section{Objectives}

To compare the effects of bioresorbable fixation systems with titanium systems used during orthognathic surgery.

\section{Search methods}

Cochrane Oral Health's Information Specialist searched the following databases: Cochrane Oral Health's Trials Register (to 20 January 2017); the Cochrane Central Register of Controlled Trials (CENTRAL; 2016, Issue 11) in the Cochrane Library (searched 20 January 2017); MEDLINE Ovid (1946 to 20 January 2017); and Embase Ovid (1980 to 20 January 2017). We searched the US National Institutes of Health Ongoing Trials Register ClinicalTrials.gov (clinicaltrials.gov; searched 20 January 2017), and the World Health Organization International Clinical Trials Registry Platform (searched 20 January 2017) for ongoing trials. No restrictions were placed on the language or date of publication when searching the electronic databases.

\section{Selection criteria}

Randomised controlled trials comparing bioresorbable versus titanium fixation systems used for orthognathic surgery in adults.

\section{Data collection and analysis}

Two review authors independently screened the results of the electronic searches, extracted data and assessed the risk of bias of the included studies. We resolved disagreement by discussion. Clinical heterogeneity between the included trials precluded pooling of data, and only a descriptive summary is presented.

Resorbable versus titanium plates for orthognathic surgery (Review)

Copyright ( 2017 The Cochrane Collaboration. Published by John Wiley \& Sons, Ltd. 


\section{Main results}

This review included two trials, involving 103 participants, one comparing titanium with resorbable plates and screws and the other titanium with resorbable screws. Both studies were at high risk of bias and provided very limited data for the primary outcomes of this review. All participants in one trial suffered mild to moderate postoperative discomfort with no statistically significant difference between the two plating groups at different follow-up times. Mean scores of patient satisfaction were 7.43 to 8.63 (range 0 to 10) with no statistically significant difference between the two groups throughout follow-up. Adverse effects reported in one study were two plate exposures in each group occurring between the third and ninth months. Plate exposures occurred mainly in the posterior maxillary region, except for one titanium plate exposure in the mandibular premolar region. Known causes of infection were associated with loosened screws and wound dehiscence with no statistically significant difference in the infection rate between titanium (3/196), and resorbable $(3 / 165)$ plates.

\section{Authors' conclusions}

We do not have sufficient evidence to determine if titanium plates or resorbable plates are superior for fixation of bones after orthognathic surgery. This review provides insufficient evidence to show any difference in postoperative pain and discomfort, level of patient satisfaction, plate exposure or infection for plate and screw fixation using either titanium or resorbable materials.

\section{PLAIN LANGUAGESUMMARY}

\section{Resorbable versus titanium plates for corrective jaw surgery}

\section{Review question}

Are resorbable (biodegradable) plates better than titanium (metal) plates for the fixation of facial bones after corrective (orthognathic) jaw surgery?

\section{Background}

Under- or overgrowth of one or both of the jaw bones can lead to reduced function and an unattractive facial appearance, either of which may have lasting and significant psychosocial effects. Treatment of severe cases may require a combination of orthodontic appliances and orthognathic (corrective jaw) surgery. After surgery the cut bone needs to be immobilised to ensure that optimal healing takes place. Titanium plates used for fixation are recognised to be the 'gold standard' but recent developments in biomaterials have led to an increased use of bioresorbable plates or screws for corrective jaw surgery. The use of bioresorbable plates for the fixation of facial bones might appear to reduce the need for a further operation for the removal of metal plates. However, whilst resorbable plates do appear to offer certain advantages over metal plates, concerns remain about the stability of fixation, the length of time required for their resorption (being reabsorbed), the possibility of foreign body reactions, and with some of the technical difficulties experienced with resorbable plates.

\section{Study characteristics}

We included two studies that analysed a total of 103 participants. The evidence in this review is up to date as of 20 January 2017. Study participants were adults older than 16 years of age. One study compared titanium with resorbable plates and screws and the other titanium with resorbable screws. One study was conducted in China, the other in Germany.

\section{Key results}

Both studies were at high risk of bias and provided very limited data. We do not have sufficient evidence to determine if titanium plates or resorbable plates are superior for the fixation of bones after corrective jaw surgery. This review provides insufficient evidence to show any difference in postoperative pain and discomfort, level of patient satisfaction, plate exposure or infection for plate and screw fixation using either titanium or resorbable materials.

\section{Quality of the evidence}

Both included studies were assessed as being at high risk of bias and the very limited and weak evidence was of very low quality. 


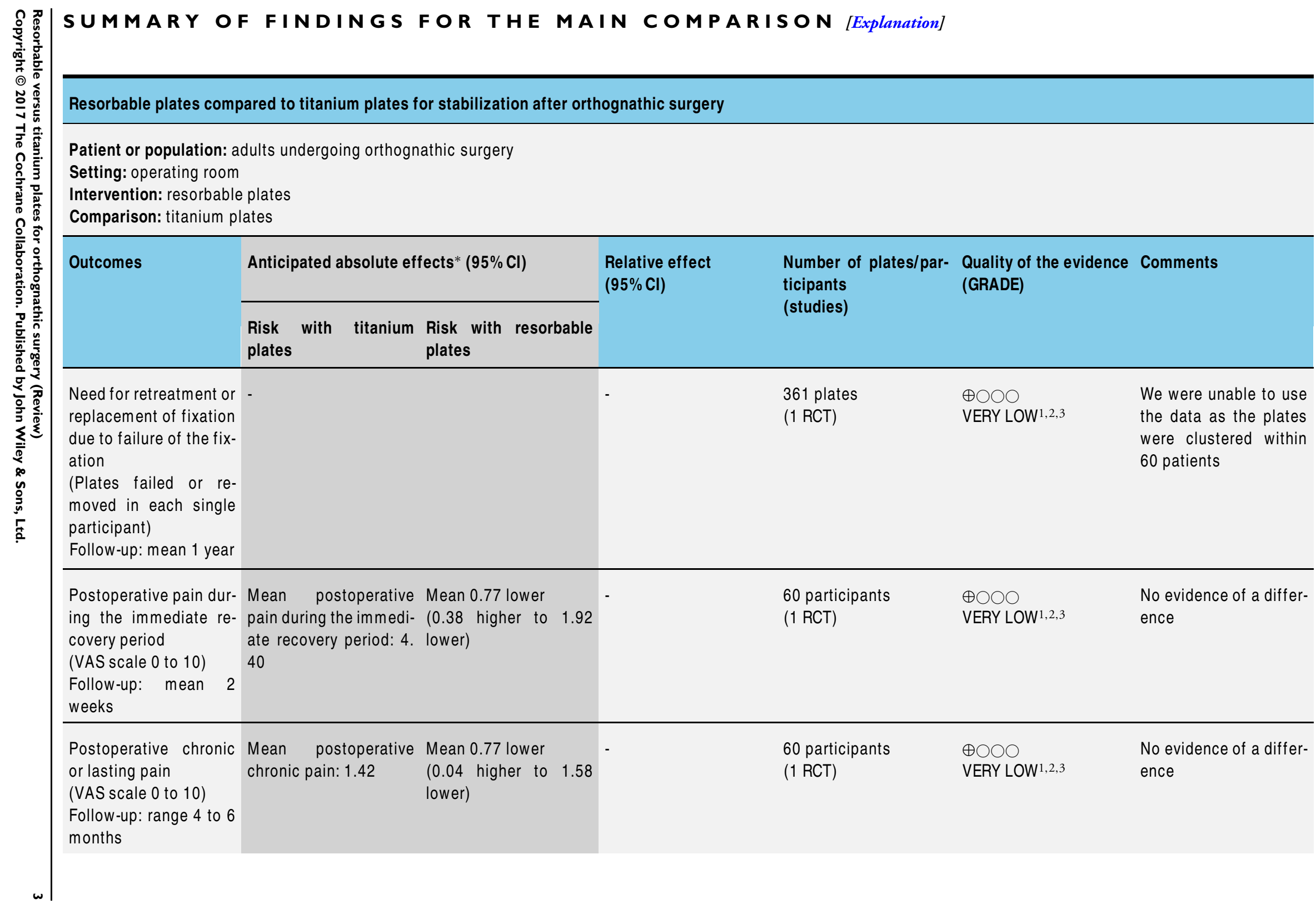




\begin{tabular}{|c|c|c|c|c|}
\hline Adverse effects & $\begin{array}{l}\text { - Exposure of the plate: both titanium and } \\
\text { resorbable groups experienced } 2 \text { plate } \\
\text { exposures which occurred between the third and } \\
\text { ninth month with plate exposure rates for the } \\
\text { titanium group of } 1.02 \% \text {, and } 1.21 \% \text { for the } \\
\text { resorbable group } \\
\text { - Superficial wound infection: } 3(10 \%) \text { of the } \\
\text { patients in each group developed infections } \\
\text { accounting for } 6 \text { plates ( } 3 / 196(1.53 \%) \text { in the } \\
\text { titanium group and } 3 / 165 \text { ( } 1.82 \%) \text { in the } \\
\text { resorbable group) } \\
\text { - Occurrence of sinus tract: } 5 \text { patients ( } 3 \text { in } \\
\text { the titanium group and } 2 \text { in the resorbable } \\
\text { group) developed a non-infected sinus tract } \\
\text { - Wound dehiscence: } 3 \text { patients ( } 10 \%) \text { in the } \\
\text { titanium group and } 2 \text { patients }(6.7 \%) \text { in the } \\
\text { resorbable group presented with wound } \\
\text { dehiscence } \\
\text { - Plate removal: rates were } 1.53 \%(3 / 196) \text { of } \\
\text { the titanium plates and } 3.63 \%(6 / 165) \text { of the } \\
\text { resorbable ones. Out of a total of } 9,2 \text { in each } \\
\text { group were removed because of plate exposure, } \\
1 \text { patient in the titanium and } 3 \text { patients in the } \\
\text { resorbable group because of infection, and } 1 \\
\text { patient in the resorbable group for non-purulent } \\
\text { sinus tract }\end{array}$ & $\begin{array}{l}60 \text { participants } \\
\text { (1 RCT) }\end{array}$ & $\begin{array}{l}\oplus \circ \bigcirc \bigcirc \\
\text { VERY LOW1,3,4 }\end{array}$ & \\
\hline
\end{tabular}

* The risk in the intervention group (and its 95\% confidence interval) is based on the assumed risk in the comparison group and the relative effect of the intervention (and its $95 \% \mathrm{Cl})$.

Cl: confidence interval; MD: mean difference; RCT: randomised controlled trial; RR: risk ratio; VAS: visual analogue scale. 


\section{GRADE Working Group grades of evidence}

High quality: we are very confident that the true effect lies close to that of the estimate of the effect

Moderate quality: we are moderately confident in the effect estimate: the true effect is likely to be close to the estimate of the effect, but there is a possibility that it is substantially different

Low quality: our confidence in the effect estimate is limited: the true effect may be substantially different from the estimate of the effect

Very low quality: we have very little confidence in the effect estimate: the true effect is likely to be substantially different from the estimate of effect

'Downgraded 1 level for indirectness (single study).

Downgraded 1 level for imprecision.

BDowngraded 1 level for high risk of performance and detection bias.

${ }^{4}$ Downgraded 1 level for inconsistency as subgroup populations of different osteotomies are included. Le-Fort I osteotomy

and mandibular osteotomies were all grouped and compared as 1. Different subgroups should have been compared separately

for consistency. 


\section{B A C K G R O U N D}

\section{Description of the condition}

Under- or over-developmental growth of one or both of the jaw bones can lead to reduced function in addition to an unattractive facial appearance, either of which may have lasting and significant psychosocial effects on the individual (Rumsey 2005). Orthodontic treatment may be useful if the discrepancies are minor, but in more severe cases a combination of treatment with orthodontic appliances and orthognathic (corrective jaw) surgery may be required. This combined treatment can be time consuming, complex, costly and very demanding of both patient and clinician (Bousaba 2002).

\section{Description of the intervention}

After orthognathic surgery the sectioned (cut) bone needs to be fixed or immobilised to ensure that healing takes place. Previously the only method of achieving this was by intraosseous wiring coupled with rigid intermaxillary (upper to lower jaw) fixation. More recent developments in biomaterials have led to an increased usage of titanium and bioresorbable osteosynthesis plates or screws, either separately or in combination, to achieve fixation.

\section{How the intervention might work}

Titanium plates are considered the 'gold standard' for internal fixation in craniomaxillofacial surgery and although they are reportedly biocompatible, titanium particles, which are thought to be due to corrosion of the titanium, have been found in scar tissue covering these plates as well as in locoregional lymph nodes. As the need for fixation is only temporary, at least until the bone has united, the removal of these plates after completion of the healing process has been advocated (Haers 1998) and although there does not appear to be a consensus in agreement for their removal, this is routinely undertaken in some countries. Some of the additional disadvantages of these metallic materials relate to their extreme stiffness which it is suggested may cause stress shielding of the underlying bone. The potential shortcomings of metallic fixation devices used in orthopaedic and orthognathic surgery are fairly well recognised and have led to the development of plates manufactured from bioresorbable materials e.g. polylactic acid, polyglycolic acid, and polydioxanone.

The use of these biologically inert and resorbable plates for the fixation of facial bones in orthognathic surgery would appear to offer some clinical advantages over metal plates by eliminating the possible need for a second operation for their removal (Mohamed-Hashem 2000; Simon 1997). Also, combinations of titanium and resorbable plates have been used for internal fixation of isolated zygomatic (cheek bone) maxillary complex (ZMC) fractures in the adult (Cheung 2004; Hochuli-Vieira 2005). In another study, orthognathic surgery was completed on the maxilla (upper jaw) with rigid fixation using titanium miniplates and screws in addition to bone biological plates, the combination of which seemed to substantially improve skeletal stability (Costa 2005).

\section{Why it is important to do this review}

Resorbable plates do appear to offer certain advantages over metal plates, but concerns remain about the stability of fixation, the length of time required for their degradation and the possibility of foreign body reactions. It is also reported that resorbable plates when used alone may not be able to withstand the physiological forces of masticatory muscles (Hanemann 2005). Clinical complications such as inflammatory foreign body reactions, osteolysis around screws and delayed resorption have been reported with the use of polylactic acid and polyglycolic acid materials (Bergsma 1993; Mohamed-Hashem 2000). In addition, a small number of material-related failures have been seen when these resorbable materials were used in bimaxillary procedures without postoperative rigid intermaxillary fixation (Haers 1998). Postoperative infection is another important complication which can occur with either system. Loose screws and wound dehiscence have been implicated, either of which may lead to plate exposure and subsequent early plate removal (Cheung 2004). It is imperative to find out which material out of the two is better. This review compares the use of titanium versus bioresorbable plates in orthognathic surgery and is an update of the Cochrane Review first published in 2007 (Fedorowicz 2007).

\section{O B J E C T I VES}

To compare the effects of bioresorbable fixation systems with titanium systems used in orthognathic surgery.

\section{METHODS}

\section{Criteria for considering studies for this review}

\section{Types of studies}

Randomised controlled trials (RCTs) comparing bioresorbable and titanium plates used for orthognathic surgery. 


\section{Types of participants}

Adults (>16 years old) undergoing orthognathic surgery. We excluded fracture patients.

\section{Types of interventions}

Titanium plates or screws (used as lag screws) or both and bioresorbable plates or screws or both.

\section{Types of outcome measures}

Assessment which included a follow-up period of up to 3 years postoperatively after any of the interventions.

\section{Primary outcomes}

(1) Need for retreatment or replacement of fixation due to failure of the fixation.

(2) Status of occlusion e.g. Angle's classification, ANB or Wits analysis as assessed by an independent assessor and the inclusion of any subjective assessment by the patient.

(3) Facial appearance and profile; judged by the patient or clinician.

(4) Immediate postoperative assessment of swelling using photography or digital morphometry.

(5) Degree of function postoperatively (mastication, swallowing, speech).

(6) Satisfactory radiographic appearance postoperatively using cephalometric radiographs (lateral and postero-anterior).

(7) Postoperative pain during the immediate recovery period and any chronic or lasting pain measured using any validated visual analogue scale (VAS).

(8) Analgesic medication used: type, dose, frequency.

\section{Secondary outcomes}

We also considered any of the following self-reported outcomes.

(1) Quality of life as assessed by a validated questionnaire.

(2) Patient satisfaction assessed by questionnaire.

\section{Costs}

Direct costs of the fixation materials, hospital bed days, and costs of the need for retreatment.

\section{Adverse effects}

Details of any adverse events where recorded and reported were considered, and included.

- Insufficient fixation.

- Re-operation and revision rate separated into minor revision (closed reduction) or major revision (removal of the plates or open reduction of the osteotomy).

- Exposure of the plate.
- Dislocation of the plate.

- Non-union of the osteotomy within the follow-up period (the definition of non-union as used within each individual study).

- Superficial wound infection (infection of the wound without evidence of spread towards the site of the plates).

- Deep wound infection (infection around the plates).

- Occurrence of sinus tract.

- Wound dehiscence.

- Postoperative blood loss (units packed cells given to a patient).

- Thromboembolic complications (deep vein thrombosis or pulmonary embolism).

- Any medical complication.

- Persistent pain at the final follow-up assessment and the use of medication, dose and type.

- Loss of sensation or function or both, without recovery within the follow-up period.

- Giant cell/foreign body or clinically diagnosed inflammatory reaction around the bioresorbable implant.

- Post-traumatic dystrophy within the follow-up period.

\section{Search methods for identification of studies}

\section{Electronic searches}

Cochrane Oral Health's Information Specialist conducted systematic searches in the following databases for randomised controlled trials and controlled clinical trials. There were no language, publication year or publication status restrictions:

- Cochrane Oral Health's Trials Register (searched 20 January 2017) (Appendix 1);

- Cochrane Central Register of Controlled Trials

(CENTRAL; 2016, Issue 11) in the Cochrane Library (searched 20 January 2017) (Appendix 2);

- MEDLINE Ovid (1946 to 20 January 2017) (Appendix 3);

- Embase Ovid (1980 to 20 January 2017) (Appendix 4).

Subject strategies were modelled on the search strategy designed for MEDLINE Ovid.

\section{Searching other resources}

We searched the following trial registries for ongoing studies:

- US National Institutes of Health Ongoing Trials Register ClinicalTrials.gov (clinicaltrials.gov; searched 20 January 2017) (Appendix 5);

- World Health Organization International Clinical Trials Registry Platform (apps.who.int/trialsearch; searched 20 January 2017) (Appendix 6). 
Only handsearching done as part of the Cochrane Worldwide Handsearching Programme and uploaded to CENTRAL was included.

We searched the reference lists of included studies and relevant systematic reviews for further studies.

We did not perform a separate search for adverse effects of interventions used, we considered adverse effects described in included studies only.

\section{Data collection and analysis}

\section{Selection of studies}

The abstracts of studies resulting from the searches were independently assessed by two review authors (Anirudha Agnihotry (AA) and Zbys Fedorowicz (ZF)) and all irrelevant studies were excluded. Full copies of all relevant and potentially relevant studies, those appearing to meet the inclusion criteria, or for which there were insufficient data in the title and abstract to make a clear decision, were obtained. These two review authors independently assessed the full-text copies and any disagreement on the eligibility of included studies was resolved through discussion. Studies not matching the inclusion criteria were excluded and eliminated from further review and their details and reasons for their exclusion were noted in the Characteristics of excluded studies table.

\section{Data extraction and management}

Study details and outcomes data were collected independently and in duplicate by two review authors (AA and ZF) using a predetermined form designed for this purpose. Data were only included if there was an independently reached consensus. Any disagreements were discussed and agreed without the need for consultation with a third review author (Karanjot S Gill (KSG).

We extracted the following details.

(1) Study methods: method of allocation, masking of participants and outcomes, exclusion of participants after randomisation and proportion of follow-up losses.

(2) Participants: country of origin of the study, sample size, age, sex, inclusion and exclusion criteria.

(3) Intervention: type of plate or screw, number used, location and length of time in follow-up.

(4) Control: either of the two interventions used as a control.

(5) Outcomes: as described in the section on outcome measures.

\section{Assessment of risk of bias in included studies}

Two review authors then graded the selected studies separately according to the domain-based evaluation described in the Cochrane Handbook for Systematic Reviews of Interventions Version 5.1.0 (updated March 2011) (Higgins 2011). The gradings were compared and any inconsistencies between the review authors were discussed and resolved.

The following domains were assessed as at 'low', 'unclear' or 'high' risk of bias:

1. sequence generation;

2. allocation concealment;

3. blinding (of participants, personnel and outcomes assessors);

4. incomplete outcome data;

5. selective outcome reporting; and

6. other sources of bias.

We categorised and reported the overall risk of bias in the included studies according to the following:

- low risk of bias (plausible bias unlikely to seriously alter the results) if all criteria were met;

- unclear risk of bias (plausible bias that raises some doubt about the results) if one or more criteria were assessed as unclear;

- high risk of bias (plausible bias that seriously weakens confidence in the results) if one or more criteria were not met.

These assessments are reported in the Characteristics of included studies table and also graphically.

\section{Measures of treatment effect}

We had planned to transform longevity/survival data to dichotomous outcomes (failure/not). Risk ratios and their $95 \%$ confidence intervals would be calculated for all dichotomous data. The mean difference and $95 \%$ confidence intervals would be calculated for continuous data.

\section{Unit of analysis issues}

It is possible that studies included in future updates may present data from repeated observations on participants which may lead to unit of analysis errors, if so we will follow the advice provided in section 9.3.4 of the Cochrane Handbook for Systematic Reviews of Interventions (Higgins 2011).

\section{Dealing with missing data}

For future updates, if data are missing attempts will be made to contact the trial investigators. There were missing data in Weidner 2005 but contact information for the author could not be tracked down, as it was not mentioned in the manuscript.

\section{Assessment of heterogeneity}

If further studies are included in future updates, we will assess clinical heterogeneity by examining the characteristics of the studies, the similarity between the types of participants, the interventions and outcomes as specified in the criteria for included studies. Clinical heterogeneity here could exist in populations with different 
types of osteotomies, e.g. Le Fort osteotomy, mandibular setback, etc.

Statistical heterogeneity will be assessed using a $\mathrm{Chi}^{2}$ test and the $\mathrm{I}^{2}$ statistic where $\mathrm{I}^{2}$ values over $60 \%$ indicate moderate to substantial heterogeneity (Higgins 2011). If this could be explained by clinical reasoning and a coherent argument can be made for combining the studies, we will enter these into a meta-analysis. In cases where the heterogeneity could not be adequately explained, the data will not be pooled. A cut-off $\mathrm{P}$ value of $>0.10$ would be used to determine statistical significance.

\section{Assessment of reporting biases}

If a sufficient number ( $>10)$ of trials investigating similar interventions are identified for inclusion in future updates of this review, publication bias will be assessed according to the recommendations on testing for funnel plot asymmetry as described in section 10.4.3.1 of the Cochrane Handbook for Systematic Reviews of Interventions (Higgins 2011). If asymmetry is identified, we will try to assess other possible causes and these will be explored in the discussion if appropriate.

\section{Data synthesis}

If further studies are included in future updates the following methods of data synthesis will apply. Data will be analysed using Review Manager software (RevMan 2014) and reported according to Cochrane criteria. Pooling of data will only occur if the included studies have similar interventions involving similar participants. We will present odds ratios for adverse effect outcomes. Any data obtained from visual analogue scales and any categorical outcomes will be transformed into dichotomous data prior to analysis if appropriate. Risk ratios, the number needed to treat and their 95\% confidence intervals will be calculated and combined for all dichotomous data; and mean differences and their $95 \%$ confidence intervals for continuous data. Our general approach would be to use a random-effects model. Additional tables were used to report results from studies not suitable for inclusion in a meta-analysis.

\section{Subgroup analysis and investigation of heterogeneity}

If a sufficient number of studies with moderate to substantial heterogeneity (as defined above) are identified we will carry out subgroup analyses based on different types of osteotomies.

\section{Sensitivity analysis}

We had expected to be able to conduct sensitivity analyses to assess the robustness of our review results by repeating the analysis with the following adjustments: exclusion of studies at high risk of bias and unpublished studies. However, the only two studies that matched our inclusion criteria were too clinically heterogeneous, so no sensitivity analyses were carried out.

\section{Presentation of main results}

We produced a 'Summary of findings' table for our main comparison (resorbable versus titanium plates for fixation of bones after orthognathic surgery) and the following outcomes listed according to priority.

1. Need for retreatment or replacement of fixation due to failure of the fixation.

2. Postoperative pain during the immediate recovery period and any chronic or lasting pain measured using any validated visual analogue scale (VAS).

3. Quality of life and self-reported patient satisfaction assessments.

4. Adverse events.

We used GRADE methods (GRADE 2004), and the GRADEpro online tool for developing 'Summary of findings' tables ( www.guidelinedevelopment.org). We assessed the quality of the body of evidence for each comparison and outcome by considering the overall risk of bias of the included studies, the directness of the evidence, the inconsistency of the results, the precision of the estimates, and the risk of publication bias. We categorised the quality of each body of evidence as high, moderate, low, or very low.

\section{R E S U L T S}

\section{Description of studies}

\section{Results of the search}

A study flow chart is presented in Figure 1. 
Figure I. PRISMA flow chart.

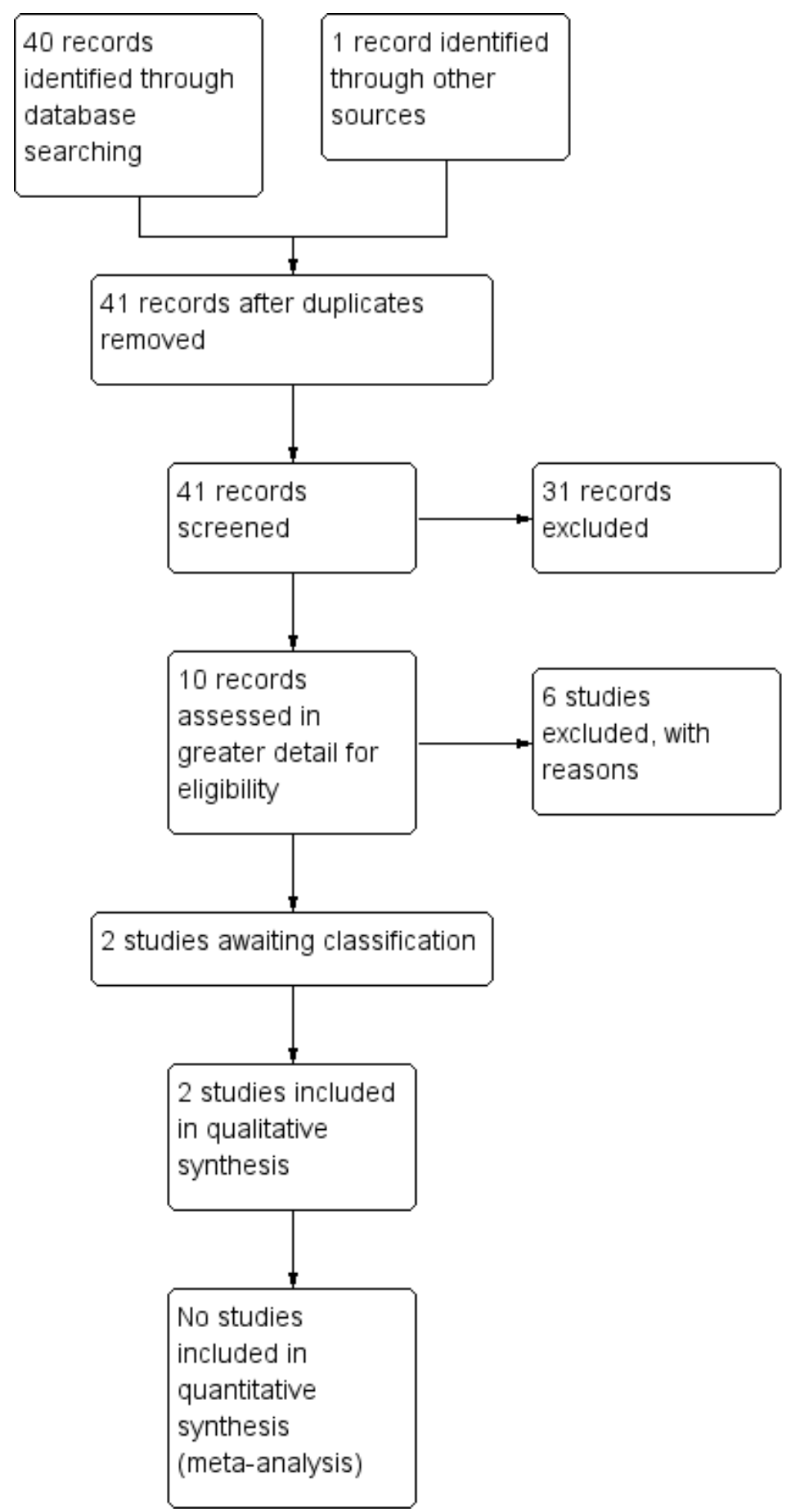


The search strategy retrieved 40 (2 Cochrane Oral Health's Trials Register, 4 CENTRAL, 15 Embase, 19 MEDLINE) references to studies. Our search of the Internet retrieved one additional and potentially eligible study (Weidner 2005). This study was a doctoral thesis in the German language which we translated and assessed for eligibility and have included in this review. After removing duplicates and examination of the titles and abstracts, all but 10 studies were discarded. Where possible, we obtained full-text copies of these potentially relevant records and their bibliographical references were also examined. After further assessment, six studies were excluded, two studies are awaiting assessment, and finally two studies matched the inclusion criteria for this review (Cheung 2004; Weidner 2005).

\section{Included studies}

\section{Characteristics of trials and setting}

Cheung 2004 was a prospective randomised controlled trial conducted in the Oral and Maxillofacial Surgery Unit of the University of Hong Kong, China from July 2001 to April 2003. Weidner 2005 was a prospective randomised controlled trial conducted in the Medical Faculty of the Würzburg University, Germany from June 1995 to April 1997.

\section{Characteristics of the participants}

A total of 103 participants across the two studies were included. One study (Cheung 2004) included surgeries to correct maxillary and mandibular deformities, while the other (Weidner 2005) included exclusively mandibular surgeries.

Sixty adults (18 male, 42 female), of 16 to 37 years (mean 22.9) of age, entered Cheung 2004. The majority of participants (61.7\%) were aged between 20 and 29 years, and the remainder were aged between 16 and 19 years (28.3\%), and between 30 and 39 years (10\%). In both intervention groups, the male to female ratio was $1: 2.3$. All of the participants had previously attended the Orthognathic Assessment Clinic for management of their dentofacial deformities and had completed their orthodontic treatment prior to entering the study. Facial deformities of the maxilla accounted for $60 \%(36 / 60)$ maxillary hypoplasia, $26.7 \%(16 / 60)$ excessive vertical maxillary height, and 8.3\% (5/60) maxillary dentoalveolar hyperplasia of the participants enrolled into the trial. The remaining $5 \%$ of participants had anterior open bites with maxillary hyperplasia. Mandibular deformities in the participants included 30\% (18/60) with mandibular hyperplasia, 21.7\% (13/60) mandibular dentoalveolar hyperplasia, 20\% (12/60) unilateral condylar hyperplasia with mandibular asymmetry, 13.3\% (8/60) mandibular hypoplasia, and 15\% (9/60) had normally proportioned mandibles.
Of the total, 6.7\% (4/60) were also diagnosed with geniohypoplasia.

Sixty adults requiring either a mandibular setback or advancement procedure entered Weidner 2005, 12 of which were eventually excluded due to insufficient data and a further five who underwent an alternative surgical procedure were also excluded. All of the 43 (27 female, 16 male) participants underwent a forward advancement procedure of the mandible. The majority (56\%) were aged 20 to 29 years, $30 \%$ were 30 to 39 years, $9 \%$ were aged below 20 years, and $5 \%$ were over 40 years of age. Patients who needed bimaxillary osteotomy or who had a history of immunodeficiency disease, cancer, any skin diseases, infections, alcoholism, rheumatism or had a fractured mandible were excluded from the study. Prior to surgery all of the participants underwent orthodontic treatment, with the stated objective of providing "a satisfactory vertical, sagittal and transverse alignment of the dental arches." No additional details of any preoperative treatment were provided in this report. At enrolment all participants received a "clinical and functional assessment" which included a subjective and objective analysis of any symptoms, measurement of their maximal jaw opening and recording of the occlusal relationship of the standing teeth.

\section{Characteristics of the interventions}

In Cheung 2004, all of the participants underwent orthognathic surgery: Le Fort I (28.8\%), maxillary subapical osteotomy (5\%), mandibular subapical osteotomy (19.2\%), mandibular body osteotomy (3.4\%), vertical subsigmoid (32.2\%), sagittal split $(8.5 \%)$, and genioplasty $(3.4 \%)$. The patients were randomised prior to surgery to either a resorbable plating group $(n=30)$ or a titanium plating group $(\mathrm{n}=30)$ for fixation. The Compact 2.0 pure titanium plating system (Mathys Medical Ltd, Bettlach, Switzerland) was used for the titanium group, and the BiosorbFX bioresorbable fixation system (Bionx Implants Inc, Tampere, Finland) made of self-reinforced poly-L/DL lactic acid copolymer (70\% Llactide and $30 \%$ D-lactide) for the resorbable group. The study included 177 osteotomies, of which 87 were fixated with 196 titanium plates and 784 titanium screws, and 90 osteotomies were fixated with 165 resorbable plates and 658 resorbable screws.

In Weidner 2005, all 43 participants underwent a set back procedure of the mandible consisting of a retromolar sagittal osteotomy (Obwegeser and Dal-Pont). They were randomised to either titanium screws (Stryker-Leibinger) $(\mathrm{n}=20)$, or resorbable screws (Isosorb®-Schraube, Aesculap Tuttlingen) $(\mathrm{n}=23)$ made of biodegradable lactopolymer (Poly- (L-co-DL-LA) (90/10))/(Poly (DL-LA) (80/20)). The report provided very little detail on the exact surgical procedure other than that two screws were used in each procedure and placed where possible either side of the mandibular canal and that no additional external fixation was used in either 
group.

\section{Characteristics of the outcomes}

Cheung 2004 followed up participants 2 weeks, 6 weeks, 3 months, 6 months, 1 year, and 2 years postoperatively. Of the 60 patients, 48 (24 titanium, 24 resorbable) were followed up for at least 1 year and six patients from the titanium group and seven from the resorbable group were reviewed for at least 2 years. A set of standard radiographs was taken at each follow-up appointment in addition to a recording of the number and type of broken plates and screws. Postoperative self-assessments were carried out by the patients, using a visual analogue scale (VAS) (0 to 10), for wound discomfort $(0=$ pain free, $10=$ severe pain $)$, clinical stability of the osteotomy segment $(0=$ very mobile, $10=$ no mobility $)$, satisfaction with the result ( $0=$ very unsatisfied, $10=$ very satisfied $)$, and palpability of the plates. Objective assessments which were made postoperatively by the surgeons included: wound dehiscence, noninfected sinus formation, plate exposure, the degree of palpability of the plates, the mobility of the osteotomised segments and the presence of infection based on pain, swelling and pus discharge. In Weidner 2005, participants were examined and had lateral skull radiographs taken at six time intervals: before orthodontic treatment (T0), preoperatively (T1), 0 to 3 months postoperatively (T2), 4 to 8 months postoperatively (T3), 9 to 14 months postoperatively (T4), and 15 months postoperatively (T5). Attendance by the 43 participants for follow-up appointments was inconsistent and consequently the number of lateral skull radiographs taken at different time periods was incomplete i.e. at the T0 appointment (21 resorbable, 18 titanium), T1 (18 resorbable, 19 titanium), T2 (7 resorbable, 8 titanium), T3 (14 resorbable, 16 titanium), T4 (7 resorbable, 7 titanium), T5 (15 resorbable, 8 titanium). Postoperative changes in several parameters (SNB angle, ANB angle, SNPog angle, mandibular inclination, Gonion angle), were recorded and analysed by a computer program after scanning of the lateral skull radiographs. The stability of these parameters was evaluated at the follow-up appointments.

\section{Excluded studies}

We excluded six studies from this review for the following reasons.

- Not or unclear if a randomised controlled trial (Ballon 2012; Ferretti 2002; Yoshioka 2012).

- Study included fracture patients (Bakelen 2013; Böhm 1998; Buijs 2012).

See Characteristics of excluded studies table for more details.

\section{Studies awaiting classification}

See Characteristics of studies awaiting classification. The authors of NCT00240669 were contacted to ascertain if the study, a clinical trial registry, has been published yet (Additional Table 1). Reyneke 2001 is an abstract and we were not able to acquire any further details about it, as of yet. If further details become available for either of these studies they will be assessed for eligibility and included, if appropriate, in future updates of this review, otherwise they will be excluded.

\section{Risk of bias in included studies}

Figure 2; Figure 3. Both included studies were at high overall risk of bias.

Figure 2. Risk of bias graph: review authors' judgements about each risk of bias item presented as percentages across all included studies.

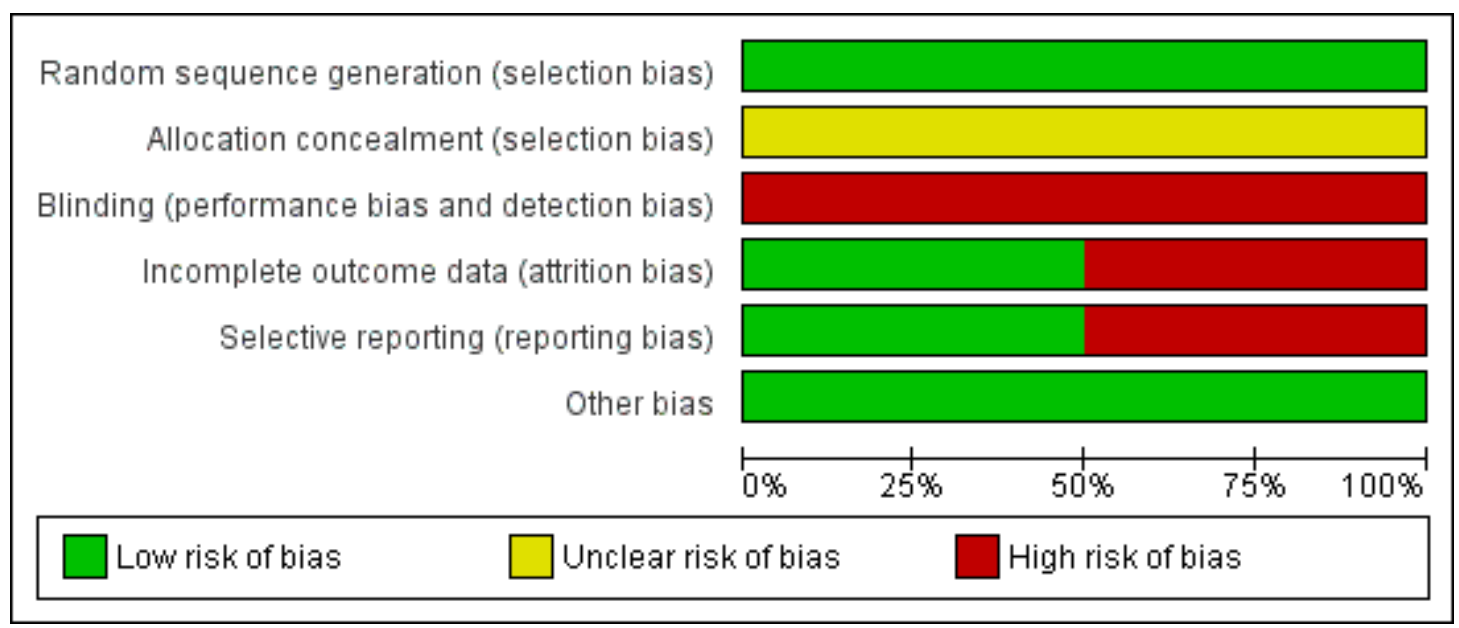

Resorbable versus titanium plates for orthognathic surgery (Review) 
Figure 3. Risk of bias summary: review authors' judgements about each risk of bias item for each included study.

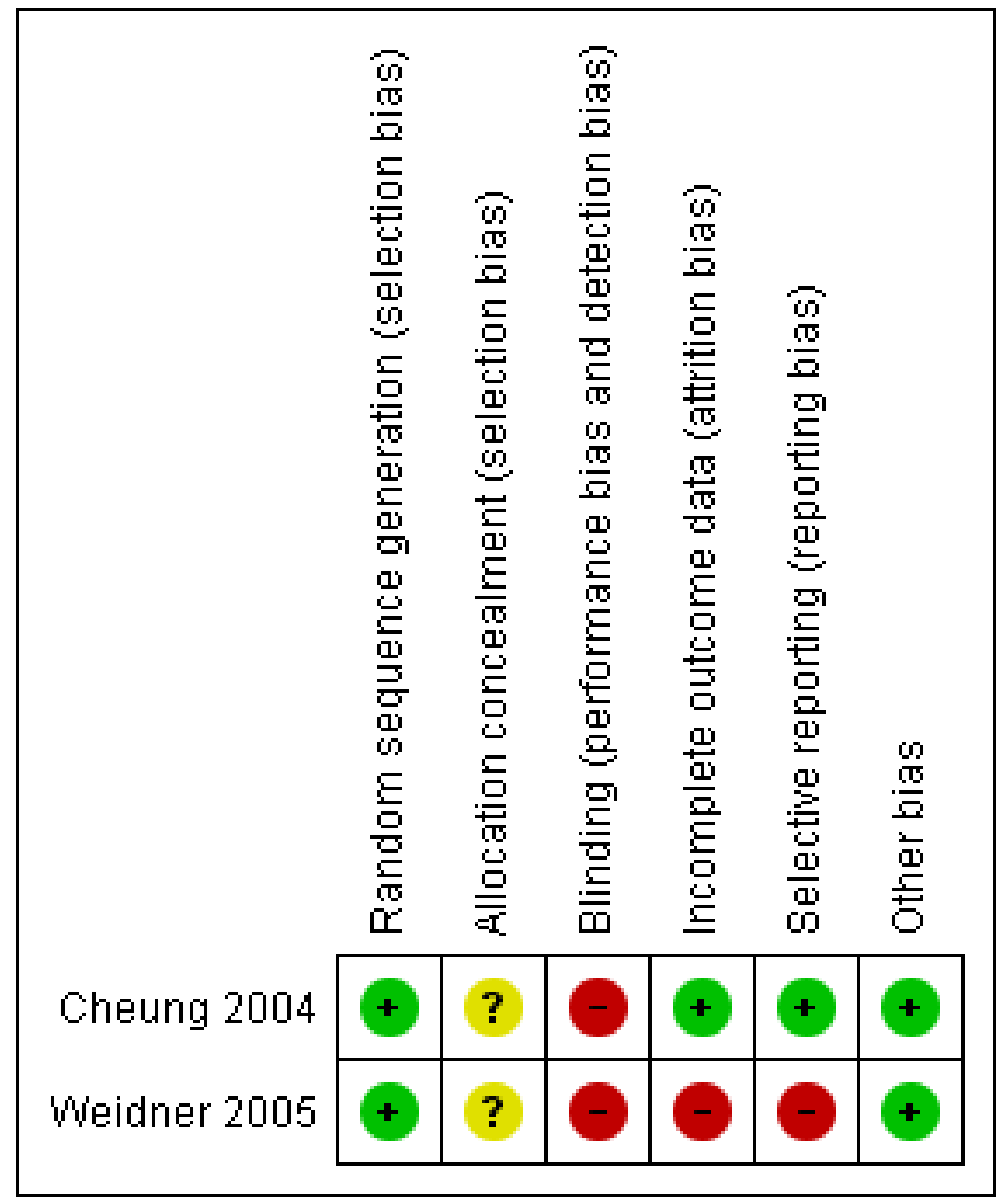

\section{Allocation}

Both included studies are at unclear risk of selection bias.

\section{Random sequence generation}

Both included studies described an adequate method of generating a random sequence: Cheung 2004 used a randomisation table while Weidner 2005 used a computer-generated sequence from a data centre. We assessed them as at low risk of bias.

\section{Allocation concealment}

Resorbable versus titanium plates for orthognathic surgery (Review)

Copyright $\odot 2017$ The Cochrane Collaboration. Published by John Wiley \& Sons, Ltd.
None of the included studies described any methods used to conceal the random sequence, so we assessed them as at unclear risk of bias.

\section{Blinding}

Both included studies were at high risk of performance and detection bias. It is unclear whether participants, operators or assessors were blinded, but in view of the nature of the intervention, blinding of the surgeons to the type of intervention was not possible in the studies. As some of the postoperative clinical outcomes were evaluated by the surgeons, who were most likely aware which of 
the patients had received which intervention, this criterion was graded as high risk. In addition, metal plates can be easily identified from resorbable plates and postoperative examination of either plates can reveal the nature of the material, hence the high risk assessment.

\section{Incomplete outcome data}

Weidner 2005 reported 28\% individuals were lost to follow-up but the reasons were not mentioned and we were unable to contact the authors for clarification, therefore we assessed the study as at high risk of attrition bias. There was no attrition for Cheung 2004, so we assessed it as low risk.

\section{Selective reporting}

For Cheung 2004, this was assessed as low risk as all the outcomes mentioned in the methods were reported fully in the results. The investigators in Weidner 2005 indicated in their report that they had intended to evaluate a number of subjective and objective outcomes, specifically those that were relevant to the postoperative occlusion, but ultimately provided very limited data even for these outcomes. Therefore this study was assessed as at high risk for this domain.

\section{Other potential sources of bias}

We did not consider there to be any issues arising from other potential sources of bias in any of the studies and we therefore assessed them both as at low risk of other bias.

\section{Effects of interventions}

See: Summary of findings for the main comparison Resorbable plates compared to titanium plates for stabilization after orthognathic surgery

See Summary of findings for the main comparison.

\section{Resorbable versus titanium plates/screws for stabilization after orthognathic surgery}

Clinical heterogeneity in the trials precluded any possibility of synthesising the data from these two studies and as they only provided limited data relevant to some of the primary and secondary outcomes, as specified in the inclusion criteria for this review, we present only these data and include a descriptive summary of results. See Additional Table 2; Table 3; Table 4.

\section{Primary outcomes}

(1) Need for retreatment or replacement of fixation due to failure of the fixation
Only Cheung 2004 reported the need for retreatment or replacement of fixation due to failure of the fixation. Although no precise data were available indicating a need for retreatment a total of nine plates were removed, $1.53 \%(3 / 196)$ in the titanium group, and $3.63 \%(6 / 165)$ in the resorbable group. The reasons for their removal are discussed further in 'Adverse effects'.

The mean change in clinical stability of the osteotomy segments ranged from 8.10 at 0 to 2 weeks to 8.93 at 4 to 6 months in the titanium group, and from 8.47 to 9.63 in the resorbable group for the same time periods (Additional Table 2).

(2) Status of occlusion e.g. Angle's classification, ANB or Wits analysis as assessed by an independent assessor and the inclusion of any subjective assessment by the patient

Weidner 2005 provided us with analyses of the mean changes in ANB, which were made from the scanned radiographs with the aid of a computer program. The ANB data, which were incomplete for many of the five time periods because of poor attendance at follow-up, were reported as 'grad' and not as the conventionally accepted 'angles'.

In order that the data could be more readily and widely understood we transformed the data from 'grad' into 'degrees' using the online convertor www.1728.com/angles.htm?b0=6 (accessed 31 January 2017). However, as a result of inconsistencies in the original data these transformed measured values cannot be considered interpretable in a quantitative sense and therefore the conclusions reached may be suspect. In the absence of any reliable data reflecting treatment outcomes for the active intervention or comparison, in this trial, we have not included any of the data for this outcome in our review.

(3) Facial appearance and profile; judged by the patient or clinician

No data available for this outcome.

(4) Immediate postoperative assessment of swelling using photography or digital morphometry

Though Cheung 2004 reported the presence of postoperative swelling, it was only noted in conjunction with infection and pus discharge, but assessment of this outcome did not include the use of photography or digital morphometry.

(5) Degree of function postoperatively (mastication, swallowing, speech)

No data available for this outcome. 
(6) Satisfactory radiographic appearance postoperatively using cephalometric radiographs (lateral and posteroanterior)

No data available for this outcome.

(7) Postoperative pain during the immediate recovery period and any chronic or lasting pain measured using any validated visual analogue scale (VAS)

In Cheung 2004, the patients rated their wound discomfort using a VAS (0 to 10). All patients suffered a mild to moderate amount of discomfort from the oral wound following the orthognathic surgery.

The severity of wound discomfort reduced gradually and there was no statistically significant difference between the titanium and resorbable plating groups at all time periods during follow-up (Additional Table 3). As there were only data available for wound discomfort for all participants in both groups up to the 4 to 6 months period, the mean difference (MD) and confidence interval (CI) for these data have been calculated as -0.77 ( $95 \%$ CI -1.58 to 0.04 ; $\mathrm{P}=0.06$ ) (60 participants) only up to this time period (Analysis $1.1)$.

\section{(8) Analgesic medication used: type, dose, frequency}

No data available for this outcome.

\section{Secondary outcomes}

\section{(1) Quality of life as assessed by a validated questionnaire}

None of the included studies reported this.

\section{(2) Patient satisfaction assessed by questionnaire}

Cheung 2004 evaluated patient satisfaction on a VAS (0 to 10). Mean scores ranged from 7.43 to 8.63 . The highest scores in the titanium group were 8.50, and 8.63 in the resorbable group (Additional Table 4). Data which were available for 48 out of 60 participants for up to 1 year postoperatively showed a gradual improvement in patient satisfaction. Patient satisfaction scores for all participants in both groups were only available up to the 4 to 6 months period, the MD and CI for these data have been calculated as 0.17 (95\% CI -0.67 to $1.01 ; \mathrm{P}=0.69$ ) (60 participants) only up to this time period (Analysis 1.2).

\section{Costs}

None of the studies reported on the cost incurred in the treatment.

\section{Adverse effects}

Weidner 2005 did not report any adverse effects. Cheung 2004 reported the following adverse effects.

Re-operation and revision rate separated into minor revision (closed reduction) or major revision (removal of the plates or open reduction of the osteotomy)

Plate removal rates were $1.53 \%(3 / 196)$ of the titanium plates and $3.63 \%(6 / 165)$ of the resorbable ones. Out of a total of nine, two in each group were removed because of plate exposure, one patient in the titanium and three patients in the resorbable group because of infection, and one patient in the resorbable group for non-purulent sinus tract.

\section{Exposure of the plate}

Both titanium and resorbable groups experienced two plate exposures which occurred between the third and ninth month with plate exposure rates for the titanium group of $1.02 \%$, and $1.21 \%$ for the resorbable group. All of the plate exposures occurred in the posterior maxillary region, except in one titanium case which occurred in the mandibular premolar region. None of the exposed plates became infected, but all of the exposed plates ultimately required removal.

Superficial wound infection (infection of the wound without evidence of spread towards the site of the plates) and deep wound infection (infection around the plates)

The trialists did not differentiate between superficial or deep wound infection. Three $(10 \%)$ of the patients in each of the two groups developed infections accounting for six plates i.e. 3/196 $(1.53 \%)$ in the titanium group and $3 / 165(1.82 \%)$ in the resorbable group. There was no statistically significant difference in the infection rate between fixation with titanium or resorbable plates $\mathrm{P}=0.83$ (published value $\mathrm{P}=0.67$ ).

All three of the infected plates in the resorbable group were removed in order to resolve the infection. One infected plate in the titanium group was removed but the remaining two titanium plates were retained and the infection was resolved by wound irrigation and antibiotic therapy. The trialists stated that infections in the resorbable group occurred relatively later than in the titanium group and that the causes of infection appeared to be related to loosened screws and wound dehiscence.

\section{Occurrence of sinus tract}

Five patients (three in the titanium group and two in the resorbable group) developed a non-infected sinus tract. The sinus tracts arose earlier in the titanium group (sixth week) than in the resorbable group (third and sixth month). Three of the tracts in the titanium 
group and one in the resorbable group resolved spontaneously after irrigation only. The one remaining patient in the resorbable group eventually required removal of the affected plate connected to the sinus tract.

\section{Wound dehiscence}

Three patients $(10 \%)$ in the titanium group and two patients $(6.7 \%)$ in the resorbable group presented with wound dehiscence. One patient in each group with dehisced wounds became infected. All the non-infected wounds closed spontaneously in less than 6 months postoperatively.

No further data were available for any of the following adverse effects.

- Insufficient fixation.

- Dislocation of the plate.

- Non-union of the osteotomy within the follow-up period

(the definition of non-union as used within each individual study).

- Postoperative blood loss (units packed cells given to a patient).

- Thromboembolic complications (deep vein thrombosis or pulmonary embolism).

- Any medical complication.

- Persistent pain at the final follow-up assessment and the use of medication, dose and type.

- Loss of sensation or function or both, without recovery within the follow-up period.

- Giant cell/foreign body or clinically diagnosed

inflammatory reaction around the bioresorbable implant.

- Post-traumatic dystrophy within the follow-up period.

\section{DISCUSSION}

\section{Summary of main results}

This review included two trials, involving 103 participants, one comparing titanium with resorbable plates and screws and the other titanium with resorbable screws. Both studies were at high risk of bias and provided very limited data for the primary outcomes of this review. We found insufficient evidence to show any difference in postoperative discomfort, level of patient satisfaction, plate exposure or infection for plate and screw fixation using either titanium or resorbable materials. Adverse effects reported in one study were two plate exposures in each group occurring between the third and ninth months. See Summary of findings for the main comparison.

\section{Overall completeness and applicability of evidence}

Overall, this review shows there is lack of evidence on the effects of using titanium or resorbable plates for stabilization of bones after orthognathic surgery. Not all outcomes were reported in the studies included, and those which were reported, do not give us any statistically or clinically significant effects favouring either plate. One study reported high attrition rate, and for long-term patientrelated outcomes of wound discomfort and satisfaction, there was also high attrition. High adherence and follow-up should be maintained for these outcomes. There was also considerable heterogeneity in the population, in terms of the jaw being treated.

Stricter protocols should be instilled that encourage adherence to follow-up and the inclusion of outcome measures such as objective postoperative aesthetic, functional, and morbid status of the participants right after the surgery.

\section{Quality of the evidence}

We included two randomised controlled trials analysing 103 participants. We found insufficient evidence to determine if titanium plates or resorbable plates are superior for fixation of bones after orthognathic surgery. The very limited and weak evidence was considered to be of very low quality. The reasons for downgrading were mostly due to imprecision (wide confidence intervals), indirectness (single study), high risk of performance and detection bias (blinding being a major limitation of these studies as it is quite impractical to blind the operating surgeon as metal can be easily identified from bioresorbable plates), and inconsistency (a subgroup analysis should have been performed for one study (Cheung 2004) which considered maxillary and mandibular osteotomies as the same population).

\section{Potential biases in the review process}

The effects of language bias while identifying and selecting studies for inclusion in a systematic review is widely recognised; thus, we ensured that language was not an exclusion criterion. We made all attempts in limiting biases in the review process by performing a comprehensive search for potentially eligible studies. The authors' independent assessments of study eligibility for inclusion in this review minimised the potential for selection bias. Although it would be acceptable to think that the comprehensive searches will have identified all existing randomised controlled trials, and thereby helped to limit bias in the conduct of this review, the absence of any high-quality published trials for surgical approach over recent years creates measure of uncertainty and there could be some unpublished studies which might add to the overall evidence. 


\section{Agreements and disagreements with other studies or reviews}

Three reviews have been published comparing resorbable and metal plates, and all three of them state that resorbable plates are as stable as metal plates (Al-Moraissi 2015; Joss 2009; Yang 2014). This Cochrane Review sought high-level evidence for the effects of bioresorbable fixation systems compared with titanium systems used for orthognathic surgery. Only two eligible studies were included in this review, one of which solely evaluated the orthodontic related treatment results of both plating systems and provided very little other data.

Whilst recognising the methodological limitations of these two studies, their clinical heterogeneity, the incompleteness of their data relevant to this systematic review, and the likelihood of bias in respect of outcome assessment in both, we have nevertheless chosen to include them but advise some caution in the interpretation of their results.

\section{A U THORS' CONCLUSIONS}

\section{Implications for practice}

We do not have sufficient evidence to determine if titanium plates or resorbable plates are superior for fixation of bones after orthognathic surgery. This review provides insufficient evidence to show any difference in postoperative pain and discomfort, level of patient satisfaction, plate exposure or infection for plate and screw fixation using either titanium or resorbable materials.

\section{Implications for research}

The results of this systematic review confirm the necessity for further larger sampled, methodologically sound trials that are reported according to the CONSORT statement (www.consortstatement.org/). Although further research is required, the possibility exists that well-informed patients may be unwilling to consent unwittingly to enrolment into a trial where they may be allocated to titanium plating, more especially if there is likely to be a requirement for follow-up surgery to remove the titanium plates after healing has taken place.

Trialists should recognise and try to ensure that any patient-reported outcomes, especially if used to measure pain, are supported by a validated and internationally recognised pain scale that has the discriminatory capacity in terms of both bandwidth and fidelity appropriate for this type of intervention. The value of these patient-reported outcomes could be further enhanced by trialists reporting the type, amount and frequency of any analgesia used to control and relieve postoperative pain. In addition, consideration should be given to the inclusion of outcome measures that assess the ability of patients to eat, swallow and speak, as well as any other postoperative functional disabilities which might arise after orthognathic surgery.

To help minimise the effects of systematic bias in outcome assessment it would be prudent if in future trials the trialists or the surgeons carrying out the intervention are not included as evaluators of outcomes and that appropriate training is given to independent assessors to ensure standardisation of criteria to be used in any outcome assessments.

Costs, not least of all in low- to middle-income countries, are an important consideration in the provision of care and therefore it would be beneficial if future randomised controlled trials for this research question could provide more information on the costs of materials, equipment used with each of the fixation systems, and direct and indirect costs related to hospitalisation and lost time from work or employment.

\section{ACKNOWLEDGEMENTS}

The review authors of this update would like to acknowledge Luisa Fernandez Mauleffinch for her constant support and advice, and Anne Littlewood for conducting the searches and supporting us with finding the full texts.

From the previous versions of the review, we would like to thank Peter Drews for his earlier contribution to writing the background for this review in addition to several colleagues from Cochrane Oral Health: Emma Tavender for her assistance in helping to develop the protocol and Sylvia Bickley for designing the search strategy. We would also like to acknowledge Hamad Aljufairi, of the Bahrain Branch of the UK Cochrane Centre, who very kindly rechecked the statistical analyses in the included studies and Helen Travess who provided valuable insight into the interpretation of the ANB data. 


\section{R E F E R E N C E S}

\section{References to studies included in this review}

Cheung 2004 \{published data only\}

Cheung LK, Chow LK, Chiu WK. A randomized controlled trial of resorbable versus titanium fixation for orthognathic surgery. Oral Surgery, Oral Medicine, Oral Pathology, Oral Radiology, and Endodontics 2004;98(4):386-97.

Weidner 2005 \{unpublished data only\}

Weidner A. Osteosynthesis with Resorbable Plates in Comparison with Conventional Titanium Osteosynthesis Screws in the Sagittal Fracture with the Obwegeser and Dal-Pont Method in a Randomized Controlled Prospective Clinical Trial. A Cephalometric Comparison [Osteosynthese mit der resorbierbaren Isosorb $®-S c h r a u b e$ im Vergleich zur konventionellen Titanosteosyntheseschraube bei der sagittalen Spaltung nach Obwegeser und Dal-Pont im Rahmen einer randomisierten, kontrollierten, prospektiven, klinischen Studie Ein röntgenkephalometrischer Vergleich] [Dissertation].

Würzburg: Universität Würzburg, 2005.

\section{References to studies excluded from this review}

Bakelen 2013 \{published data only\}

van Bakelen N, Buijs J, Jansma J, Stegenga B, Bos $\mathrm{R}$. Biodegradable versus titanium osteosynthesis in maxillofacial surgery: results of a multicenter randomized controlled trial. International Journal of Oral and Maxillofacial Surgery 2013;42(10):1339.

Ballon 2012 \{published data only\} Ballon A, Laudemann K, Sader R, Landes CA. Segmental stability of resorbable $\mathrm{P}(\mathrm{L} / \mathrm{DL}) \mathrm{LA}-\mathrm{TMC}$ osteosynthesis versus titanium miniplates in orthognatic surgery. Journal of Cranio-maxillo-facial Surgery 2012;40(8):e408-14.

Böhm 1998 \{published data only\} Böhm H, Pistner H, Barth T, Reuther J, Mühling J. Bioresorbable screws in comparison with titanium screws for osteosynthesis after sagittal fracture of the mandible - a prospective, randomized, controlled clinical study [Bioresorbierbare Schrauben im Vergleich zu Titanschrauben fur die Osteosynthese nach sagittaler Spaltung des Unterkiefers--Eine prospektive, randomisierte, kontrollierte klinische Studie]. Biomedizinische Technik 1998;43 Suppl:542-3.

Buijs 2012 \{published data only\}

Buijs GJ, van Bakelen NB, Jansma J, de Visscher JG, Hoppenreijs TJ, Bergsma JE, et al. A randomized clinical trial of biodegradable and titanium fixation systems in maxillofacial surgery. Journal of Dental Research 2012;91(3): 299-304.

Ferretti 2002 \{published data only\}

Ferretti C, Reyneke JP. Mandibular, sagittal split osteotomies fixed with biodegradable or titanium screws: a prospective, comparative study of postoperative stability. Oral Surgery, Oral Medicine, Oral Pathology, Oral Radiology, and Endodontics 2002;93(5):534-7.
Yoshioka 2012 \{published data only\}

Yoshioka I, Igawa K, Nagata J, Yoshida M, Ogawa Y, Ichiki

$\mathrm{T}$, et al. Comparison of material-related complications after bilateral sagittal split mandibular setback surgery: biodegradable versus titanium miniplates. Journal of Oral and Maxillofacial Surgery 2012;70(4):919-24.

\section{References to studies awaiting assessment}

\section{NCT00240669 \{unpublished data only\}}

NCT00240669. RESTIT: evaluation of resorbable osteosynthesis devices versus titanium in maxillofacial surgery [RESTIT: evaluation of resorbable osteosynthesis devices versus titanium in maxillofacial surgery - a prospective randomized trial in therapeutic strategy]. clinicaltrials.gov/show/NCT00240669 (first received 14 October 2005).

Reyneke 2001 \{published data only\}

Reyneke J, Ferretti C. Le Fort I maxillary osteotomies fixed with biodegradable or titanium plates: a prospective comparative study. International Journal of Oral and Maxillofacial Surgery 2001;30 Suppl A:S49.

\section{Additional references}

\section{Al-Moraissi 2015}

Al-Moraissi EA, Ellis E 3rd. Biodegradable and titanium osteosynthesis provide similar stability for orthognathic surgery. Journal of Oral and Maxillofacial Surgery 2015;73 (9):1795-808.

\section{Bergsma 1993}

Bergsma EJ, Rozema FR, Bos RR, de Bruijn WC. Foreign body reactions to resorbable poly(L-lactide) bone plates and screws used for the fixation of unstable zygomatic fractures. Journal of Oral and Maxillofacial Surgery 1993;51 (6):666-70

Bousaba 2002

Bousaba S, Siciliano S, Delatte M, Faes J, Reychler H. Indications for orthognathic surgery, the limitations of orthodontics and of surgery. Revue Belge de Medecine Dentaire 2002;57(1):9-23.

\section{Costa 2005}

Costa F, Robiony M, Zerman N, Zorzan E, Politi M. Bone biological plate for stabilization of maxillary inferior repositioning. Minerva Stomatologica 2005;54(4):227-36.

\section{GRADE 2004}

Atkins D, Best D, Briss PA, Eccles M, Falck-Ytter Y, Flottorp $S$, et al. Grading quality of evidence and strength of recommendations. BMJ 2004;328(7454): 1490.

\section{Haers 1998}

Haers PE, Suuronen R, Lindqvist C, Sailer H. Biodegradable polyactides plates and screws in orthognathic surgery: technical note. Journal of Cranio-maxillo-facial Surgery 1998;26(2):87-91. 


\section{Hanemann 2005}

Hanemann M Jr, Simmons O, Jain S, Baratta R, Guerra $A B$, Metzinger SE. A comparison of combinations of titanium and resorbable plating systems for repair of isolated zygomatic fractures in the adult: a quantitative biomechanical study. Annals of Plastic Surgery 2005;54(4): $402-8$.

Higgins 2011

Higgins JP, Green S, editor(s). Cochrane Handbook for Systematic Reviews of Interventions Version 5.1.0 (updated March 2011). The Cochrane Collaboration, 2011. Available from handbook.cochrane.org.

\section{Hochuli-Vieira 2005}

Hochuli-Vieira E, Cabrini Gabrielli MA, Pereira-Filho VA, Gabrielli MF, Padilha JG. Rigid internal fixation with titanium versus bioresorbable miniplates in the repair of mandibular fractures in rabbits. International Journal of Oral and Maxillofacial Surgery 2005;34(2):167-73.

Joss 2009

Joss CU, Vassalli IM. Stability after bilateral sagittal split osteotomy advancement surgery with rigid internal fixation: a systematic review.. Journal of Oral and Maxillofacial Surgery 2009;67(2):301-13.

\section{Mohamed-Hashem 2000}

Mohamed-Hashem IK, Mitchell DA. Resorbable implants (plates and screws) in orthognathic surgery. Journal of Orthodontics 2000;27(2):198-9.

RevMan 2014 [Computer program] Nordic Cochrane Centre, The Cochrane Collaboration. Review Manager 5 (RevMan 5). Version 5.3. Copenhagen:
Nordic Cochrane Centre, The Cochrane Collaboration, 2014.

Rumsey 2005

Rumsey N, Harcourt D. The Psychology of Appearance. Oxford: Oxford University Press, 2005.

Simon 1997

Simon JA, Ricci JL, Di Cesare PE. Bioresorbable fracture fixation in orhopedics: a comprehensive review. Part I. Basic science and preclinical studies. American Journal of Orthopedics 1997;26(10):665-71.

\section{Yang 2014}

Yang L, Xu M, Jin X, Xu J, Lu J, Zhang C, et al. Skeletal stability of bioresorbable fixation in orthognathic surgery: a systemic review. Journal of Cranio-maxillo-facial Surgery 2014;42(5):e176-81.

\section{References to other published versions of this review}

\section{Fedorowicz 2006}

Fedorowicz Z, Nasser M, Newton JT, Oliver RJ. Resorbable versus titanium plates for orthognathic surgery. Cochrane Database of Systematic Reviews 2006, Issue 4. [DOI: 10.1002/14651858.CD006204

\section{Fedorowicz 2007}

Fedorowicz Z, Nasser M, Newton T, Oliver R. Resorbable versus titanium plates for orthognathic surgery. Cochrane Database of Systematic Reviews 2007, Issue 2. [DOI: 10.1002/14651858.CD006204.pub2

* Indicates the major publication for the study 


\section{CHARACTERISTICS OF STUDIES}

\section{Characteristics of included studies [ordered by study ID]}

Cheung 2004

Methods

Trial design: prospective randomised controlled study

Location: Oral and Maxillofacial unit of the University of Hong Kong, China

Study duration: July 2001 to April 2003

Participants

Adults with dentofacial deformities, with orthodontic treatment completed prior to the surgery

Exclusion criteria: any type of intraosseous pathologies (e.g. odontogenic cyst or tumours); any type of craniofacial syndromes (e.g. cleft lip and palate, hemifacial microsomia, Crouzon's syndrome, and Treacher Collin Syndrome)

Age: 16 to 37 years (mean 22.9 years)

Gender: 18 male, 42 female

Number randomised: 60 (Group A: 30; Group B: 30)

Number evaluated: 60 (Group A: 30; Group B: 30)

Interventions

Resorbable plates group $(\mathrm{n}=30)$ : BiosorbFX bioresorbable fixation system (Bionx Implants Inc, Tampere, Finland)

Titanium plates group $(n=30)$ : Compact 2.0 pure titanium plating system (Mathys Medical Ltd, Bettlach, Switzerland)

Orthognathic surgery: resorbable plates group: 24 (80\%) underwent bimaxillary surgery and $6(20 \%)$ single jaw surgery; titanium plates group: 30 (100\%) underwent bimaxillary surgery. Total osteotomies: 177

Plating: 90 osteotomies with 165 resorbable plates and 658 screws. 87 osteotomies with 196 titanium plates and 784 screws

Outcomes Intraoperative: plating time (per 1 plate 4 screws), number and type of broken plates and screws during operative procedure

Postoperative: subjective self-assessment by patients with VAS ( 0 to 10 ), wound discomfort, clinical stability of the osteotomy segment, palpability of plates and screws, overall satisfaction level with surgical result

Postoperative: objective assessment by surgeons of wound dehiscence, pus discharge, sinus formation, plate exposure, degree of palpability of plates, mobility of the osteotomy segments, the occlusion and the presence of infection (based on pain, swelling and pus discharge)

Notes $\quad$ Funding: not reported

Declarations/conflicts of interest: not reported

\section{Risk of bias}

\section{Bias} Authors' judgement

Random sequence generation (selection Low risk bias)

\section{Support for judgement}

Quote: “...patients were randomly assigned immediately before surgery to a resorbable

Resorbable versus titanium plates for orthognathic surgery (Review) 


\begin{tabular}{|c|c|c|}
\hline Allocation concealment (selection bias) & Unclear risk & Not mentioned in the text \\
\hline $\begin{array}{l}\text { Blinding (performance bias and detection } \\
\text { bias) } \\
\text { All outcomes }\end{array}$ & High risk & $\begin{array}{l}\text { Unclear whether patient, operator and as- } \\
\text { sessor blinded } \\
\text { Limitation of the study: metal plates can be } \\
\text { easily identified from resorbable plates }\end{array}$ \\
\hline $\begin{array}{l}\text { Incomplete outcome data (attrition bias) } \\
\text { All outcomes }\end{array}$ & Low risk & No attrition reported \\
\hline Selective reporting (reporting bias) & Low risk & $\begin{array}{l}\text { All the outcomes discussed in methods were } \\
\text { reported in the results }\end{array}$ \\
\hline Other bias & Low risk & None found \\
\hline
\end{tabular}

Weidner 2005

Methods

Trial design: prospective randomised controlled study
Location: Medical Facutly of the Würzburg University, Germany
Study duration: June 1995 to April 1997

Participants

Interventions

Resorbable fixation system (Isosorb®-Schraube) and titanium fixation system (StrykerLeibinger, Freiburg i.Br.). All patients underwent retromolar sagittal osteotomy (Obwegeser/Dal-Pont (1959))

Outcomes Cephalometric analysis

Adults needing a mandibular advancement or set back of about $10 \mathrm{~mm}$

Exclusion criteria: history of immunodeficiency disease, cancer, any skin diseases, infections, alcoholism, rheumatism or fractured mandible

Age: 18 to 47 years

Gender: 16 male (Group A: 9; Group B: 7), 27 female (Group A: 14; Group B: 13)

Number randomised: 60

Number evaluated: 43 (Group A: 23; Group B: 20) (12 excluded due to incomplete records, 5 allocated to alternate type of surgery)

Declarations/conflicts of interest: not reported

\section{Risk of bias}

\begin{tabular}{|c|c|c|}
\hline Bias & Authors' judgement & Support for judgement \\
\hline $\begin{array}{l}\text { Random sequence generation (selection } \\
\text { bias) }\end{array}$ & Low risk & $\begin{array}{l}\text { Computer-generated sequence from the } \\
\text { data centre }\end{array}$ \\
\hline
\end{tabular}


Weidner 2005 (Continued)

\begin{tabular}{|c|c|c|}
\hline Allocation concealment (selection bias) & Unclear risk & $\begin{array}{l}\text { It is not clear if the concealment was per- } \\
\text { formed }\end{array}$ \\
\hline $\begin{array}{l}\text { Blinding (performance bias and detection } \\
\text { bias) } \\
\text { All outcomes }\end{array}$ & High risk & $\begin{array}{l}\text { Unclear whether patient, operator and out- } \\
\text { comes assessment blinded } \\
\text { Limitation of the study: metal plates can be } \\
\text { easily identified from resorbable plates }\end{array}$ \\
\hline $\begin{array}{l}\text { Incomplete outcome data (attrition bias) } \\
\text { All outcomes }\end{array}$ & High risk & $28 \%$ individuals lost to follow-up \\
\hline Selective reporting (reporting bias) & High risk & $\begin{array}{l}\text { Investigators indicate in their report to had } \\
\text { intended to evaluate a number of subjective } \\
\text { and objective outcomes, specifically rele- } \\
\text { vant to the postoperative occlusion, but ul- } \\
\text { timately provided very limited data even for } \\
\text { these outcomes }\end{array}$ \\
\hline Other bias & Low risk & None found \\
\hline
\end{tabular}

VAS = visual analogue scale.

\section{Characteristics of excluded studies [ordered by study ID]}

\begin{tabular}{|c|c|}
\hline Study & Reason for exclusion \\
\hline Bakelen 2013 & It includes fracture patients, which is an exclude for this review. It is an abstract only, full study is not published \\
\hline Ballon 2012 & $\begin{array}{l}\text { It clearly states in the text that participants were not randomised and were given a choice to go ahead with either } \\
\text { treatment, therefore not a randomised controlled trial }\end{array}$ \\
\hline Buijs 2012 & $\begin{array}{l}\text { Participants younger than } 16 \text { were included in the study, as opposed by the inclusion criteria of this review. It } \\
\text { includes fracture patients as well }\end{array}$ \\
\hline Böhm 1998 & It includes fracture patients, which is an exclude for this review \\
\hline Ferretti 2002 & Controlled clinical trial, participants assigned deliberately rather than randomly \\
\hline Yoshioka 2012 & $\begin{array}{l}\text { Quote: "All patients were prospectively and consecutively randomized to } 2 \text { study groups." Study does not include } \\
\text { any other details on the methods used or results. Our repeated attempts to contact the study authors for further } \\
\text { clarification failed }\end{array}$ \\
\hline
\end{tabular}

Resorbable versus titanium plates for orthognathic surgery (Review)

Copyright @ 2017 The Cochrane Collaboration. Published by John Wiley \& Sons, Ltd. 


\section{Characteristics of studies awaiting assessment [ordered by study ID]}

\section{NCT00240669}

\begin{tabular}{l|l}
\hline Methods & Randomised controlled trial \\
\hline Participants & $\begin{array}{l}\text { Aged } 18 \text { to } 50 \text { years with } 1 \text { or more fractures/osteotomy of facial massif requiring a surgical setting with osteosynthesis } \\
\text { plates. Estimated enrolment: } 308 \text { participants }\end{array}$ \\
\hline Interventions & $\begin{array}{l}\text { Resorbable PLLA/PGA plates compared with usual titanium plates for osteotomies and fractures } \\
\text { Study visits: screening visit (baseline with randomisation and surgery); day 1, day 21, day } 45 \text { (traumatology)/day } 90 \\
\text { (orthognathic); month } 6,12 \text { and } 14\end{array}$ \\
\hline Outcomes & $\begin{array}{l}\text { - Quality of fractures setting and osteotomy } \\
\text { - Operative time of each surgery } \\
\text { - Clinical tolerance of the devices } \\
\text { - Pain (VAS) } \\
\text { - Local inflammation } \\
\text { - Scar disunion } \\
\text { - Infection } \\
\text { - Subcutaneous or submucous palpation of the plates }\end{array}$ \\
\hline Notes & $\begin{array}{l}\text { The recruitment status of this study is unknown. The completion date has passed and the status has not been verified } \\
\text { in more than } 2 \text { years }\end{array}$ \\
\hline
\end{tabular}

Reyneke 2001

Methods

Participants

Interventions -

Outcomes

Notes It is an abstract and there is no follow-up or published study of this abstract. The abstract was not available so we do not have any information regarding this study. Until the next review update, we will keep this on hold in this section, and if get the full-text or any other details, the data will be included for consideration

PLLA/PGA = poly-L-lactic/polyglycolic acid; VAS = visual analogue scale. 
DATA AND ANALYSES

Comparison 1. Resorbable versus titanium plating

\begin{tabular}{lcclc} 
Outcome or subgroup title & $\begin{array}{c}\text { No. of } \\
\text { studies }\end{array}$ & $\begin{array}{c}\text { No. of } \\
\text { participants }\end{array}$ & Statistical method & Effect size \\
\hline $\begin{array}{l}\text { 1 Postoperative pain (wound } \\
\text { discomfort) VAS (0-10) }\end{array}$ & 1 & & Mean Difference (IV, Fixed, 95\% CI) & Subtotals only \\
$\begin{array}{l}\text { 1.1 0-2 weeks } \\
1.24-6 \text { months }\end{array}$ & 1 & 60 & Mean Difference (IV, Fixed, 95\% CI) & -0.77 [-1.92, 0.38] \\
$\begin{array}{l}\text { 2 Patient satisfaction 4-6 months } \\
\text { postoperative }\end{array}$ & 1 & 60 & Mean Difference (IV, Fixed, 95\% CI) & $-0.77[-1.58,0.04]$ \\
\hline
\end{tabular}

\section{Analysis I.I. Comparison I Resorbable versus titanium plating, Outcome I Postoperative pain (wound discomfort) VAS (0-10).}

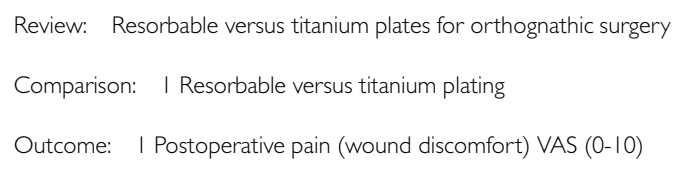

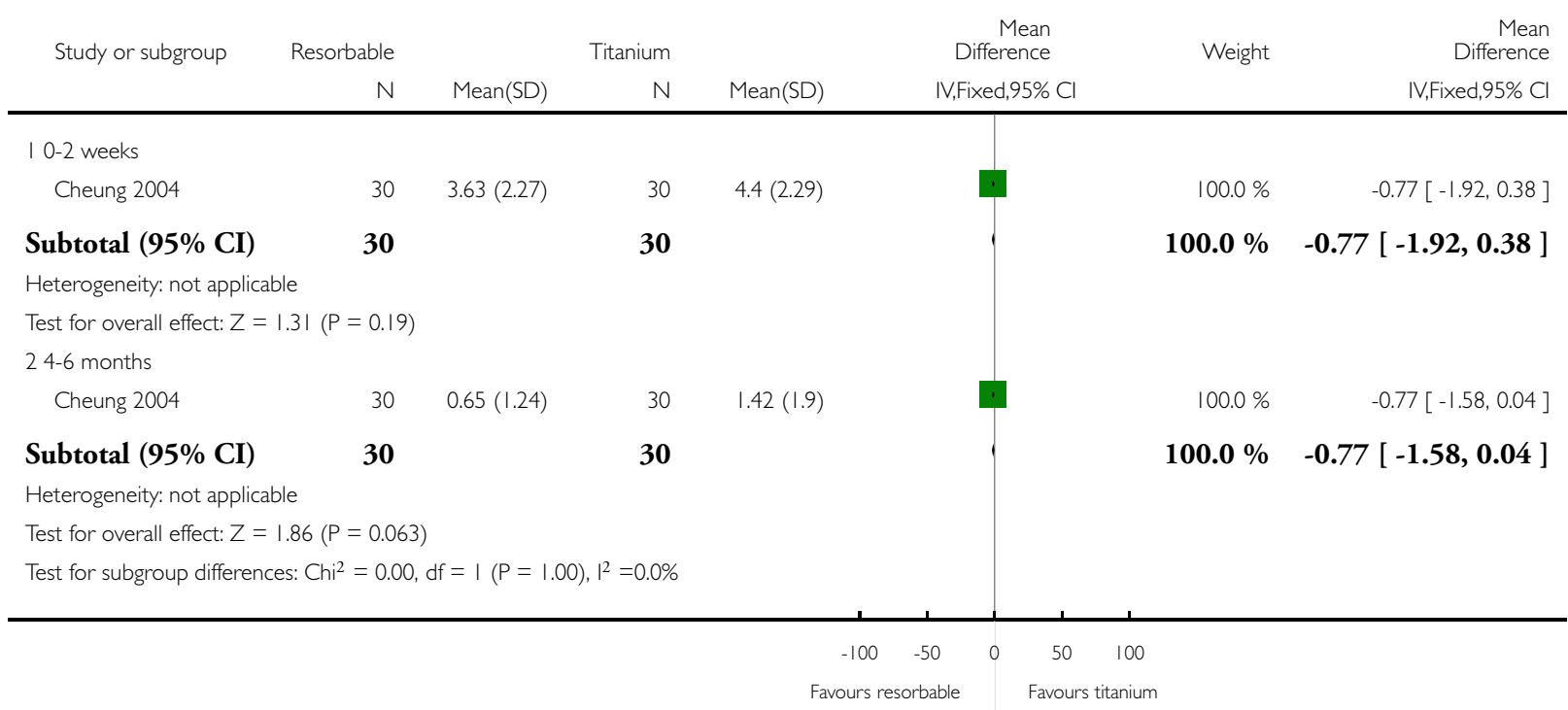




\section{Analysis I.2. Comparison I Resorbable versus titanium plating, Outcome 2 Patient satisfaction 4-6 months postoperative.}

Review: Resorbable versus titanium plates for orthognathic surgery

Comparison: I Resorbable versus titanium plating

Outcome: 2 Patient satisfaction 4-6 months postoperative

\begin{tabular}{|c|c|c|c|c|c|c|c|c|c|}
\hline \multirow[t]{2}{*}{ Study or subgroup } & \multirow{2}{*}{$\begin{array}{r}\text { Resorbable } \\
N\end{array}$} & \multicolumn{2}{|c|}{ Titanium } & \multicolumn{4}{|c|}{$\begin{array}{r}\text { Mean } \\
\text { Difference }\end{array}$} & \multirow[t]{2}{*}{ Weight } & \multirow{2}{*}{$\begin{array}{r}\text { Mean } \\
\text { Difference } \\
\text { IV,Fixed,95\% Cl }\end{array}$} \\
\hline & & Mean(SD) & $N$ & Mean(SD) & & & ked,95\% Cl & & \\
\hline Cheung 2004 & 30 & $8.47(1.43)$ & 30 & $8.3(1.86)$ & & & & $100.0 \%$ & $0.17[-0.67,1.01]$ \\
\hline Total $(95 \% \mathrm{CI})$ & 30 & & 30 & & & & $\rightarrow$ & $100.0 \%$ & $0.17[-0.67,1.01]$ \\
\hline \multicolumn{10}{|c|}{ Heterogeneity: not applicable } \\
\hline \multicolumn{10}{|c|}{ Test for overall effect: $Z=0.40(P=0.69)$} \\
\hline \multicolumn{10}{|c|}{ Test for subgroup differences: Not applicable } \\
\hline & & & & & -10 & -5 & 5 & 10 & \\
\hline \multicolumn{10}{|c|}{ Favours resorbable $\quad$ Favours titanium } \\
\hline
\end{tabular}

\section{ADDITIONAL TABLES}

Table 1. Correspondence with study authors for missing details

\begin{tabular}{|c|c|c|}
\hline Study ID & Email query by review authors & Response from trialists \\
\hline NCT00240669 & $\begin{array}{l}8 \text { September } 2016 \\
\text { "Dear Dr Bouletreau, } \\
\text { We are updating a Cochrane systematic review compar- } \\
\text { ing resorbable and non-resorbable plates in orthognathic } \\
\text { surgeries. } \\
\text { Your trial registered in clinicaltrials.gov is a potential } \\
\text { include, if completed: } \\
\text { 'RESTIT: evaluation of resorbable osteosynthesis de- } \\
\text { vices versus titanium in maxillofacial surgery: a prospec- } \\
\text { tive } \\
\text { randomized trial in therapeutic strategy' kindly share the } \\
\text { results. } \\
\text { Best" }\end{array}$ & No response \\
\hline
\end{tabular}


Table 2. Clinical stability of osteotomy segments (Cheung 2004)

\begin{tabular}{l|lll}
\hline Postoperative period & Titanium - Mean $(\mathrm{SD})$ & Resorbable - Mean $(\mathrm{SD})$ & P value \\
\hline 0-2 weeks & $8.10(1.79)(\mathrm{n}=30)$ & $8.47(2.18)(\mathrm{n}=30)$ & 0.48 \\
\hline 3-6 weeks & $8.50(1.70)(\mathrm{n}=30)$ & $9.07(1.48)(\mathrm{n}=30)$ & 0.17 \\
\hline 7-12 weeks & $8.97(1.94)(\mathrm{n}=30)$ & $9.10(1.83)(\mathrm{n}=30)$ & 0.79 \\
\hline 4-6 months & $8.93(1.89)(\mathrm{n}=30)$ & $9.63(0.76)(\mathrm{n}=30)$ & 0.09 \\
\hline 6-12 months & $9.54(0.83)(\mathrm{n}=24)$ & $9.67(1.09)(\mathrm{n}=24)$ & 0.40 \\
\hline $\begin{array}{l}\text { 12-24 months } \\
\text { SD = standard deviation. }\end{array}$ & $8.8(1.94)(\mathrm{n}=6)$ & $9.43(0.79)(\mathrm{n}=7)$ & 0.35 \\
\hline
\end{tabular}

Table 3. Postoperative pain (wound discomfort) (Cheung 2004)

\begin{tabular}{l|lll}
\hline Postoperative period & Titanium - Mean $(\mathbf{S D})$ & Resorbable - Mean $(\mathbf{S D})$ & P value \\
\hline $0-2$ weeks & $4.40(2.29)(\mathrm{n}=30)$ & $3.63(2.27)(\mathrm{n}=30)$ & 0.19 \\
\hline 3-6 weeks & $3.13(2.26)(\mathrm{n}=30)$ & $2.33(2.16)(\mathrm{n}=30)$ & 0.16 \\
\hline 7-12 weeks & $1.47(1.50)(\mathrm{n}=30)$ & $1.20(1.35)(\mathrm{n}=30)$ & 0.47 \\
\hline 4-6 months & $1.42(1.90)(\mathrm{n}=30)$ & $0.65(1.24)(\mathrm{n}=30)$ & 0.06 \\
\hline 6-12 months & $0.67(1.13)(\mathrm{n}=24)$ & $0.46(1.10)(\mathrm{n}=24)$ & 0.52 \\
\hline $\begin{array}{l}\text { 12-24 months } \\
\text { SD = standard deviation. }\end{array}$ & $1.00(2.00)(\mathrm{n}=6)$ & $0.29(0.49)(\mathrm{n}=7)$ & 0.38 \\
\hline
\end{tabular}

SD = standard deviation.

Table 4. Patient satisfaction (Cheung 2004)

\begin{tabular}{|c|c|c|c|}
\hline Postoperative period & Titanium - Mean (SD) & Resorbable - Mean (SD) & P value \\
\hline 0-2 weeks & $7.60(1.45)(\mathrm{n}=30)$ & $7.53(1.53)(\mathrm{n}=30)$ & 0.86 \\
\hline 3-6 weeks & $7.43(2.05)(\mathrm{n}=30)$ & $8.00(1.53)(\mathrm{n}=30)$ & 0.23 \\
\hline 7-12 weeks & $8.07(1.72)(\mathrm{n}=30)$ & $8.27(1.36)(\mathrm{n}=30)$ & 0.62 \\
\hline 4-6 months & $8.30(1.86)(\mathrm{n}=30)$ & $8.47(1.43)(\mathrm{n}=30)$ & 0.68 \\
\hline
\end{tabular}


Table 4. Patient satisfaction (Cheung 2004) (Continued)

\begin{tabular}{l|lll}
\hline 6-12 months & $8.50(1.84)(\mathrm{n}=24)$ & $8.63(1.44)(\mathrm{n}=24)$ & 0.79 \\
\hline $\begin{array}{l}\text { 12-24 months } \\
\text { SD = standard deviation. }\end{array}$ & $8.00(2.37)(\mathrm{n}=6)$ & $7.57(2.50)(\mathrm{n}=7)$ & 0.76 \\
\hline
\end{tabular}

\section{A P P E N D I C E S}

\section{Appendix I. Cochrane Oral Health's Trials Register search strategy}

From March 2016, searches of the Cochrane Oral Health's Trials Register for this review were undertaken using the Cochrane Register of Studies and the search strategy below:

1 ((osteotomy or "mandibular advancement" OR “orthognathic surgery" OR (orthodontic* AND surg*)):ti,ab) AND (INREGISTER) 2 (((maxill* OR mandib*) AND (surg* OR osteotom* OR fracture*)):ti,ab) AND (INREGISTER)

3 (\#1 or \#2) AND (INREGISTER)

4 ((titanium AND (plate* Or screw* OR fix* OR stabili*))) AND (INREGISTER)

5 (((bioresorb* AND plate) OR (bioresorb* AND miniplate*) OR (bioresorb* AND fix*) OR "resorbable plate*” OR (biodegradable AND plate*) OR ("biologically inert" AND plate*) OR "biological plate*” OR ("biologically inert" AND fixat*)):ti,ab) AND (INREGISTER)

6 (\#3 and \#4 and \#5) AND (INREGISTER)

Previous searches of the Cochrane Oral Health's Trials Register were undertaken using Procite software and the search strategy below: ((osteotomy or "mandibular advancement" OR "orthognathic surgery" OR (orthodontic* AND surg*) OR ((maxill* OR mandib*) AND (surg* OR osteotom* OR fracture*))) AND (titanium AND (plate* Or screw* OR fix* OR stabili*)) AND ((bioresorb* AND plate) OR (bioresorb* AND miniplate*) OR (bioresorb* AND fix*) OR “resorbable plate*” OR (biodegradable AND plate*) OR ("biologically inert" AND plate*) OR "biological plate*” OR ("biologically inert" AND fixat*)))

\section{Appendix 2. Cochrane Central Register of Controlled Clinical Trials (CENTRAL) search strategy}

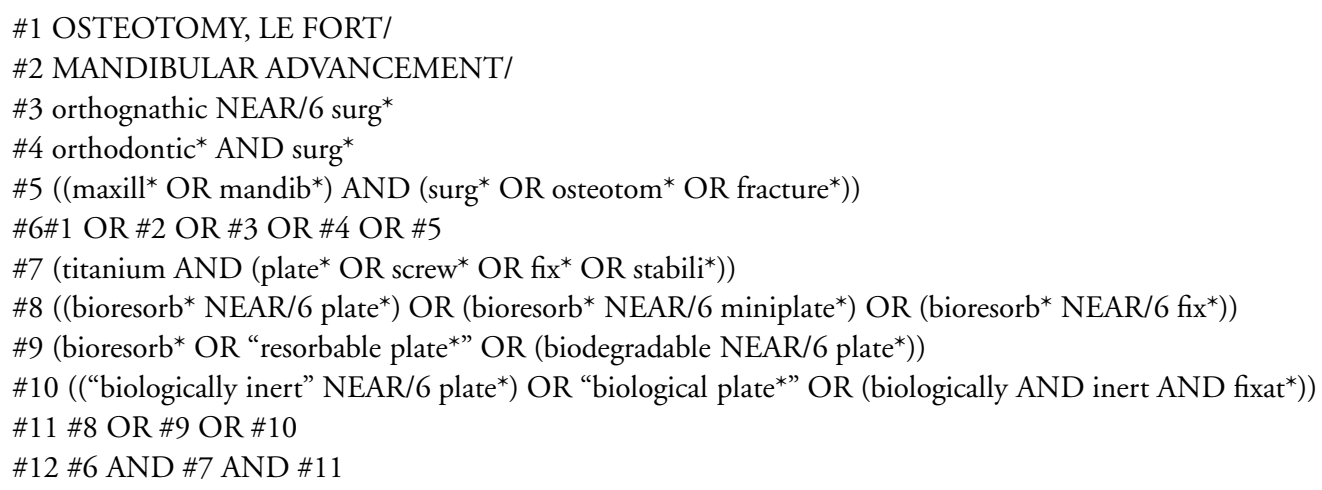

Resorbable versus titanium plates for orthognathic surgery (Review) 


\section{Appendix 3. MEDLINE Ovid search strategy}

1. Osteotomy, Le Fort/

2. Mandibular Advancement/

3. (orthognathic adj6 surg\$).mp. [mp=title, original title, abstract, name of substance word, subject heading word]

4. (orthodontic\$ and surg\$).mp. [mp=title, original title, abstract, name of substance word, subject heading word]

5. ((maxill\$ or mandib\$) and (surg\$ or osteotom\$ or fracture\$)). mp. [mp=title, original title, abstract, name of substance word, subject heading word]

6. or/1-5

7. (titanium and (plate $\$$ or screw $\$$ or fix $\$$ or stabili $\$)$ ).mp. [mp=title, original title, abstract, name of substance word, subject heading word]

8. ((bioresorb\$ adj6 plate\$) or (bioresorb\$ adj6 miniplate\$) or (bioresorb\$ adj6 fix\$)).mp. [mp=title, original title, abstract, name of substance word, subject heading word]

9. (bioresorb\$ or resorbable plate $\$$ or (biodegradable adj6 plate\$)).mp. [mp=title, original title, abstract, name of substance word, subject heading word]

10. ((biologically inert adj6 plate\$) or biological plate\$ or (biologically and inert and fixat $\$)$ ).mp. [mp=title, original title, abstract, name of substance word, subject heading word]

11. or/8-10

12. 6 and 7 and 11

\section{Appendix 4. Embase Ovid search strategy}

1. Osteotomy, Le Fort/

2. Mandibular Advancement/

3. (orthognathic adj6 surg\$).mp.

4. (orthodontic $\$$ and surg $\$$ ).mp.

5. ((maxill\$ or mandib\$) and (surg\$ or osteotom $\$$ or fracture $\$)$ ).mp.

6. or/1-5

7. (titanium and (plate $\$$ or screw $\$$ or fix $\$$ or stabili $\$)$ ).mp.

8. ((bioresorb\$ adj6 plate\$) or (bioresorb\$ adj6 miniplate\$) or (bioresorb\$ adj6 fix\$)).mp.

9. (bioresorb\$ or resorbable plate $\$$ or (biodegradable adj6 plate\$)).mp.

10. ((biologically inert adj6 plate\$) or biological plate\$ or (biologically and inert and fixat\$)).mp.

11. or/8-10

12. 6 and 7 and 11

\section{Appendix 5. US National Institutes of Health Ongoing Trials Register (ClinicalTrials.gov) search strategy}

orthognathic and titanium and resorbable

osteotomy and titanium and resorbable

\section{Appendix 6. World Health Organization International Clinical Trials Registry Platform search strategy}

orthognathic and titanium and resorbable

osteotomy and titanium and resorbable

Resorbable versus titanium plates for orthognathic surgery (Review) 
WHAT'S NEW

\begin{tabular}{lll}
\hline Date & Event & Description \\
\hline 2 November 2017 & Review declared as stable & $\begin{array}{l}\text { This review will not be updated until a substantial body of evidence on the topic } \\
\text { becomes available. If trials are conducted and found eligible for inclusion in the } \\
\text { future, the review would then be updated accordingly }\end{array}$ \\
\hline
\end{tabular}

\section{H I S T O R Y}

\begin{tabular}{l|l|l}
\hline Date & Event & Description \\
\hline 18 September 2017 & $\begin{array}{l}\text { New citation required but conclusions have not } \\
\text { changed }\end{array}$ & $\begin{array}{l}\text { Changes in authorship; searches and methods up- } \\
\text { dated; 'Summary of findings' table generated }\end{array}$ \\
\hline 18 September 2017 & New search has been performed & $\begin{array}{l}\text { Searches updated 20 January 2017. No new studies } \\
\text { found for inclusion }\end{array}$ \\
\hline 31 July 2008 & Amended & Converted to new review format \\
\hline
\end{tabular}

\section{CONTRIBUTIONS OFAUTHORS}

Anirudha Agnihotry (AA) and Zbys Fedorowicz (ZF) were responsible for co-ordinating the review, screening search results, and screening retrieved papers against the inclusion criteria.

AA organised the retrieval of papers and ZF wrote to authors of papers for additional information.

AA, ZF and KSG (Karanjot S Gill) were responsible for appraising the quality of papers.

$\mathrm{AA}$ and $\mathrm{ZF}$ were responsible for data management of the review including extracting data from papers and entering data into Review Manager software.

$\mathrm{AA}$ and $\mathrm{ZF}$ were responsible for obtaining and screening data on unpublished studies.

ZF, KSG and AA were responsible for the interpretation and analysis of data.

ZF, MN (Mona Nasser), AA and KSG all contributed to writing the review.

$\mathrm{ZF}, \mathrm{MN}$ conceived the idea for the review and $\mathrm{AA}$ is the guarantor for the review. 


\section{DECLARATIONSOF INTEREST}

There are no financial conflicts of interest and the review authors declare that they do not have any associations with any parties who may have vested interests in the results of this review.

\section{SOURCES OF SUPPORT}

\section{Internal sources}

- No sources of support supplied

\section{External sources}

- National Institute for Health Research (NIHR), UK.

This project was supported by the NIHR, via Cochrane Infrastructure funding to Cochrane Oral Health. The views and opinions expressed herein are those of the review authors and do not necessarily reflect those of the Systematic Reviews Programme, the NIHR, the NHS or the Department of Health.

- Cochrane Oral Health Global Alliance, Other.

The production of Cochrane Oral Health reviews has been supported financially by our Global Alliance since 2011 ( oralhealth.cochrane.org/partnerships-alliances). Contributors over the past year have been the American Association of Public Health Dentistry, USA; the British Association for the Study of Community Dentistry, UK; the British Society of Paediatric Dentistry, UK; the Canadian Dental Hygienists Association, Canada; the Centre for Dental Education and Research at All India Institute of Medical Sciences, India; the National Center for Dental Hygiene Research \& Practice, USA; New York University College of Dentistry, USA; NHS Education for Scotland, UK; and the Swiss Society for Endodontology, Switzerland.

\section{NOTES}

This review will not be updated until a substantial body of evidence on the topic becomes available. If trials are conducted and found eligible for inclusion in the future, the review would then be updated accordingly.

\section{INDEX TERMS}

\section{Medical Subject Headings (MeSH)}

*Absorbable Implants; *Bone Plates; *Internal Fixators; *Titanium; Bone Screws; Device Removal; Mandible [*surgery]; Maxilla [*surgery]; Osteotomy [methods]; Randomized Controlled Trials as Topic

\section{MeSH check words}

Humans 